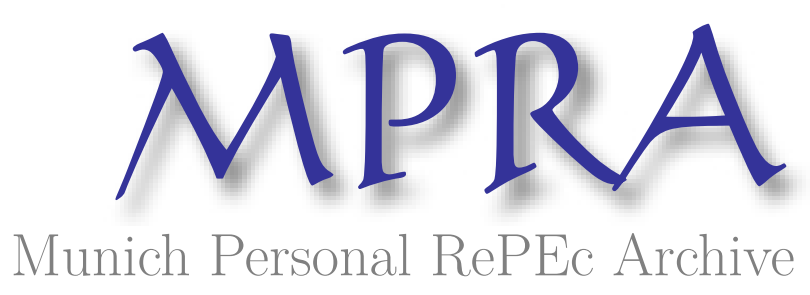

\title{
Budgetary Policies in a DSGE Model with Finite Horizons
}

\author{
Annicchiarico, Barbara and Giammarioli, Nicola and \\ Piergallini, Alessandro \\ Department of Economics, University of Rome 'Tor Vergata'
}

January 2009

Online at https://mpra.ub.uni-muenchen.de/12650/

MPRA Paper No. 12650, posted 13 Jan 2009 10:31 UTC 


\title{
Budgetary Policies in a DSGE Model with Finite Horizons*
}

\author{
Barbara Annicchiarico $^{\dagger} \quad$ Nicola Giammarioli ${ }^{\ddagger} \quad$ Alessandro Piergallini $^{\S}$
}

January 2009

\begin{abstract}
This paper presents a dynamic stochastic general equilibrium model with nominal rigidities, capital accumulation and finite horizons. Our New Keynesian framework exhibits intergenerational wealth effects and is intended to investigate the macroeconomic implications of fiscal policy, which is specified by either a debt-based tax rule or a balanced-budget rule allowing for temporary deficits. When calibrated to euro area quarterly data, the model predicts that fiscal expansions generate a trade-off in output dynamics between short-term gains and medium-term losses. It is shown that the effects of fiscal shocks crucially depend upon the conduct of monetary policy. Simulation analysis suggests that balanced-budget requirements enhance the determinacy properties of feedback interest rate rules by guaranteeing inflation stabilization.
\end{abstract}

JEL Classification: E52; E58; E63.

Keywords: Fiscal Policy; Monetary Policy; Nominal Rigidities; Capital Accumulation; Finite Horizons; Simulations.

${ }^{*}$ We are very grateful to Eric Leeper for helpful comments and suggestions. We also thank Giancarlo Marini, Luca Onorante, Jean-Pierre Vidal, Juergen von Hagen, Leopold von Thadden, seminar participants at the ECB, CeFiMS-University of London, the VII APET International Conference on Public Economics in Hanoi, the XLVII Riunione Scientifica Annuale, Società Italiana degli Economisti, in Verona, the XV International "Tor Vergata" Conference on "Banking and Finance" in Rome, and the XXII Annual European Economic Association Congress in Budapest for useful comments and discussions. Alessandro Piergallini is grateful to the Fiscal Policies Division of the European Central Bank for kind hospitality. Financial support from CNR and the FIRB project is acknowledged. The opinions expressed herein are those of the authors and do not necessarily reflect those of the European Central Bank. Earlier version circulated as ECB Working Paper No. 661 with the title "Fiscal Policy in a Monetary Economy with Capital and Finite Lifetime".

${ }^{\dagger}$ Corresponding Author: Department of Economics, University of Rome 'Tor Vergata', Via Columbia 2, 00133 Roma, Italy. E-mail: barbara.annicchiarico@uniroma2.it

$\ddagger$ European Central Bank, Fiscal Policies Division. E-mail: nicola.giammarioli@ecb.int

$\S$ Department of Economics, University of Rome 'Tor Vergata'. E-mail: alessandro.piergallini@uniroma2.it 


\section{Introduction}

The implications of different fiscal policies and the interaction between fiscal and monetary policies in terms of macroeconomic stability and price developments are key topics in the current policy debate as well as in the academic research. Fiscal discipline and sound budgetary positions are considered to be essential for macroeconomic and price stability, even in the presence of a fully independent monetary authority. This is notably reflected in the fiscal rules enshrined in the Maastricht Treaty and the Stability and Growth Pact of the European Union. ${ }^{1}$

Dynamic stochastic general equilibrium (DSGE) models, incorporating imperfect competition and nominal rigidities, are increasingly adopted as the basic tool-kit for the evaluation of monetary policy. ${ }^{2}$ However, in the infinitely-lived representative agent paradigm in which the Ricardian equivalence holds, changes in public debt have no effect on aggregate consumption and potential redistributions of wealth across generations are neglected. Fiscal policy matters for price stability mainly when it is 'active' in Leeper (1991)'s sense, that is, the stability of real public debt is not respected for any bounded sequences of all other endogenous variables. ${ }^{3}$ Alternatively, the introduction of distortionary taxation, along the lines suggested by Schmitt-Grohé and Uribe (2007), or the introduction of rule-of-thumb consumers, as proposed by Galí, López-Salido and Vallés (2004, 2007), allow to examine the non-trivial implications of 'passive' fiscal policies, when fiscal solvency is guaranteed.

In this paper we focus on a different line of research in which the Ricardian equivalence proposition is not satisfied, because the assumption of identical infinitely-lived private agents is relaxed. Starting from the finite-lifetime approach first outlined by Yaari (1965) and Blanchard (1985), we enrich the analysis by incorporating the overlapping generations (OLG) setup into a DSGE monetary model with nominal rigidities, capital accumulation and investment adjustment costs. ${ }^{4}$

We calibrate a linearized version of the model using euro area quarterly data. Fiscal policy is described by either a debt-based tax rule or a balanced-budget rule allowing for temporary deficits. Monetary policy is described by a standard Taylor rule. The proposed model is able to capture micro-founded wealth effects that influence aggregate consumption dynamics. Therefore, the LM relation and the dynamics of both public debt and asset prices matter for the monetary and fiscal policy transmission mechanisms. The

\footnotetext{
${ }^{1}$ The general government deficit should not exceed the $3 \%$ to GDP reference value and the debt to GDP ratio should be below $60 \%$ or, if above, approach to that reference value at a satisfactory pace. Furthermore, EMU Member States are required to have medium term objectives, which range from $1 \%$ deficit to close to balance or in surplus positions, depending on the country specific public debt ratio and potential growth.

${ }^{2}$ See Rotemberg and Woodford (1997, 1999), Clarida, Galí and Gertler (1999), McCallum and Nelson (1999a, 1999b), Taylor (1999a), Woodford (2003), Galí and Gertler (2007), Galí (2008), and references therein.

${ }^{3}$ See Woodford $(1998,2001,2003)$.

${ }^{4}$ Annicchiarico, Marini and Piergallini (2008) examine the interactions between monetary and fiscal policy in a baseline New Keynesian model with OLG, abstracting from capital accumulation. Leith and von Thadden (2008) analyze the issue of equilibrium determinacy in a continuous-time OLG model incorporating price stickiness and capital accumulation, in the absence of investment adjustment costs and asset price dynamics.
} 
theoretical framework we describe proves to be particularly suitable for the analysis of macroeconomic implications of fiscal and monetary policy, also when the fiscal authority aims at avoiding explosive paths for the public debt.

We use our New Keynesian model with OLG and capital accumulation to analyze the role of different fiscal policy rules for business cycle fluctuations and for the design of monetary policy. We first show that equilibrium determinacy is affected by the specification of fiscal policy. The 'Taylor principle' (the nominal interest rate responding more than one-to-one to a permanent increase in inflation ${ }^{5}$ ) might not be sufficient for equilibrium determinacy under a 'passive' feedback tax-rule of the Leeper-style. Conversely, both 'passive' and 'active' monetary policies are compatible with equilibrium uniqueness under a balanced-budget rule.

A prediction of the model is that fiscal expansions tend to generate an intertemporal trade-off: positive fiscal shocks are expansionary in the short run but are likely to generate persistent adverse effects on economic activity in the medium run, shading some light in the debate on the so called non-keynesian effects. Remarkably, it is shown that the effects of fiscal policy crucially depend on the type of monetary policy rule adopted by the central bank, providing a sound micro-founded rationale for the view, first suggested by Sims (1988), that empirical studies on the effects of fiscal policy should explicitly take into account monetary factors. ${ }^{6}$ Finally, simulation analysis supports the view that balanced-budget requirements, beyond enhancing the determinacy properties of feedback interest rate rules, are suitable for preserving price stability.

The structure of the paper is as follows. In Section 2 we present the model, derive the first order conditions and introduce the policy rules. The model is linearized around a non-stochastic steady state and calibrated to euro area quarterly data in Section 3. In Section 4 we examine equilibrium properties and dynamics under alternative fiscal and monetary policy rules. In Section 5 we develop stochastic simulations and assess the performance of different combinations of policy rules. The main conclusions are summarized in Section 6.

\section{The Model}

In this Section we develop a DSGE model extended to incorporate overlapping generations and capital accumulation. The economy consists of seven types of agents: finitely-lived consumers, perfectly competitive life insurance companies, a continuum of firms producing differentiated intermediate goods and setting nominal prices in a staggered fashion, perfectly competitive final goods firms, perfectly competitive

\footnotetext{
${ }^{5}$ See, e.g., Bullard and Mitra (2002), McCallum (2003), and Woodford (2001, 2003) for a discussion.

${ }^{6}$ See, for instance, Perotti (2002) and Mountford and Uhlig (2008) for empirical approaches along these lines.
} 
capital producers, the monetary authority and the fiscal authority.

\subsection{Consumers}

The demand-side is described by a stochastic discrete-time version of the Yaari (1965)-Blanchard (1985) OLG model with no intergenerational bequest motive, extended to include endogenous labor supply and money holding choices. ${ }^{7}$

The economy is populated by forward looking agents with identical preferences and facing the same constant probability of death, $\lambda \in(0,1)$, in each time period. Birth and death rates are the same. For analytical convenience, total population is normalized to one. Hence, in each time period a new cohort of size $\lambda$ is born and a fraction of equal size of the population dies. At time $t$ the size of the generation born at time $s \leq t$ is $\lambda(1-\lambda)^{t-s}$. Since the probability of death is constant overtime, the expected life horizon of an agent born at time $s$ is given by $\sum_{t-s=1}^{\infty}(t-s) \lambda(1-\lambda)^{t-s-1}=1 / \lambda$. It should be noted that for $\lambda \rightarrow 0$ the expected lifetime $1 / \lambda \rightarrow \infty$, i.e. agents face an infinite life horizon.

Since there is no intergenerational altruism and lifetime is uncertain, a perfectly competitive life insurance market is assumed to be operative as in Yaari (1965) and Blanchard (1985). In particular, in order to avoid unintended bequest, insurance companies collect financial wealth from the deceased members of the population and pay fair premia to survivors. The zero-profit condition in the insurance sector requires that the gross return on the insurance contract, that is incorporated into the individual flow budget constraint, is given by $1 /(1-\lambda)$.

\subsubsection{The Individual Optimization Problem}

Individuals face stochastic sequences of prices, interest rates, taxes and profit shares, and decide on consumption, real money holdings, labor supply and wealth accumulation. Real money balances yield direct utility in the spirit of Sidrauski (1967) and Brock (1975). ${ }^{8}$ Total non-human wealth consists of money, government bonds and capital.

The objective of the representative agent $j$ belonging to the generation born at time $s \leq 0$ is to maximize the following expected lifetime utility function:

$$
E_{0} \sum_{t=0}^{\infty}[\beta(1-\lambda)]^{t} U\left(C_{s, t}(j), \frac{M_{s, t}(j)}{P_{t}}, N_{s, t}(j)\right)
$$

where $\beta \in(0,1)$ is the subjective discount factor, $P_{t}$ is the price index, $C_{s, t}(j)$ is consumption of the final good, $M_{s, t}(j)$ denote end-of-period money holdings, and $N_{s, t}(j)$ represents the agent's $j$ labor, assumed

\footnotetext{
${ }^{7} \mathrm{~A}$ continuous-time monetary version of the Blanchard-Yaari framework has been previously developed by Marini and van der Ploeg (1988).

${ }^{8}$ The implications of real money balances in a DSGE model with OLG are examined in Piergallini (2006).
} 
to be supplied under monopolistic competition. Specifically, each individual $j$ faces the following demand function for her labor services: ${ }^{9}$

$$
N_{s, t}(j)=\left(\frac{W_{s, t}(j)}{W_{t}}\right)^{-\eta_{t}} N_{t}
$$

where $\eta_{t}>1$ is the elasticity of substitution between differentiated labor inputs, $N_{t}$ is total employment, $W_{s, t}(j)$ is the individual nominal wage rate, and $W_{t}$ indicates the aggregate wage index:

$$
W_{t}=\left(\sum_{s=-\infty}^{t} \int_{0}^{\lambda(1-\lambda)^{t-s}} W_{s, t}(j)^{1-\eta_{t}} d j\right)^{\frac{1}{1-\eta_{t}}}
$$

The elasticity of labor demand, $\eta_{t}$, is the same across workers, but is allowed to be time variant.

The flow budget constraint of the representative agent $j$ born at time $s$ is

$$
\begin{aligned}
& \frac{B_{s, t+1}(j)}{R_{t}}+M_{s, t}(j)+Q_{t} K_{s, t+1}(j) \\
\leq & \frac{1}{1-\lambda}\left(A_{s, t}(j)+W_{s, t}(j) N_{s, t}(j)+Z_{s, t}(j)-T_{s, t}(j)-P_{t} C_{s, t}(j)\right),
\end{aligned}
$$

where $B_{s, t}(j)$ denote nominal riskless government bonds carried over from period $t-1$ and paying one unit of numéraire in period $t, R_{t}$ denotes the gross nominal interest rate on bonds purchased in period $t, Q_{t}$ is the price of capital, $Z_{s, t}(j)$ is the share in the profits of intermediate goods firms, $T_{s, t}(j)$ denote nominal lump-sum net taxes, and $A_{s, t}(j)$ is the total beginning-of-period financial wealth given by

$$
A_{s, t}(j) \equiv B_{s, t}(j)+M_{s, t-1}(j)+\left[(1-\delta) Q_{t}+R_{t}^{k}\right] K_{s, t}(j),
$$

where $\delta$ is the depreciation rate and $R_{t}^{k}$ indicates the nominal rental rate of capital holdings, $K_{s, t}(j) .{ }^{10}$

The representative consumer $j$ of the generation born at time $s \leq 0$ chooses the set $\left\{C_{s, 0}(j)\right.$, $\left.M_{s, 0}(j), W_{s, 0}(j) B_{s, 1}(j), K_{s, 1}(j)\right\}$ and the sequences of contingency plans $\left\{C_{s, t}(j), M_{s, t}(j), W_{s, t}(j)\right.$, $\left.B_{s, t+1}(j), K_{s, t+1}(j)\right\}_{t=1}^{\infty}$ in order to maximize (1) subject to (2) and (4), given the initial wealth $A_{s, 0}(j)$ and the stochastic sequences $\left\{Z_{s, t}(j), T_{s, t}(j), R_{t}, R_{t}^{k}, P_{t}, Q_{t}, W_{t}, N_{t}\right\}_{t=0}^{\infty}$, whose exogenously given probability distributions are known by the consumers. Profit shares and lump-sum net taxes are ageindependent, while newly born agents do not hold any financial assets, for the sake of simplicity.

In order to obtain analytically tractable solutions for aggregate variables, we specialize on the following

\footnotetext{
${ }^{9}$ This demand function derives from the firms' optimizing behavior. See section 2.2 .

${ }^{10}$ It should be noticed that the flow budget constraint incorporates the fair premium payment deriving from the insurance contract. The timing convention is consistent with the discrete time versions of the Yaari-Blanchard olg model adopted by Frenkel and Razin (1986) and Smets and Wouters (2002).
} 
period utility function:

$$
U\left(C_{s, t}(j), \frac{M_{s, t}(j)}{P_{t}}, N_{s, t}(j)\right) \equiv \log \left[C_{s, t}(j)^{1-\gamma}\left(\frac{M_{s, t}(j)}{P_{t}}\right)^{\gamma}-V\left(N_{s, t}(j)\right)\right]
$$

where $V^{\prime}(\bullet), V^{\prime \prime}(\bullet)>0$. Theoretical foundations that justify the adoption of this utility function in the perpetual-youth models with endogenous labor supply are developed by Ascari and Rankin (2007). ${ }^{11}$

The solution to the consumer dynamic optimization problem yields the following first order necessary conditions:

$$
\begin{gathered}
1=\beta R_{t} E_{t}\left\{\frac{\widetilde{C}_{s, t}(j)}{\widetilde{C}_{s, t+1}(j)} \frac{P_{t}}{P_{t+1}}\right\}, \\
1=\beta E_{t}\left\{\frac{\widetilde{C}_{s, t}(j)}{\widetilde{C}_{s, t+1}(j)} \frac{P_{t}}{P_{t+1}} \frac{(1-\delta) Q_{t+1}+R_{t+1}^{k}}{Q_{t}}\right\}, \\
\frac{M_{s, t}(j)}{P_{t}}=\frac{\gamma}{(1-\gamma)(1-\lambda)} \frac{R_{t}}{R_{t}-1} C_{s, t}(j), \\
\frac{W_{s, t}(j)}{P_{t}}=\frac{1+u_{t}^{w}}{1-\gamma}\left(\frac{P_{t} C_{s, t}(j)}{M_{s, t}(j)}\right)^{\gamma} V^{\prime}\left(N_{s, t}(j)\right),
\end{gathered}
$$

where $\tilde{C}_{s, t}(j) \equiv C_{s, t}(j)-\left(P_{t} C_{s, t}(j) / M_{s, t}(j)\right)^{\gamma} V\left(N_{s, t}(j)\right)$ can be interpreted as consumption net of its 'subsistence' level (see Ascari and Rankin, 2007); expressions (7) and (8) are the stochastic Euler equations, while (9) and (10) represent the efficiency static conditions on money demand and labor supply choices, respectively. The optimality condition for labor supply incorporates the exogenous optimal wage markup $u_{t}^{w}=1 /\left(\eta_{t}-1\right)$, reflecting the agent's market power. Because wages are perfectly flexible, in the symmetric equilibrium all workers of all generations will set the same wage and supply the same hours of labor, i.e. $W_{s, t}(j)=W_{t}$ and $N_{s, t}(j)=N_{t}$ for all $j \in[0,1]$.

Let define the stochastic discount factor of the representative agent $j$ of generation $s$ as

$$
\Lambda_{t, t+1}(s, j) \equiv \beta \frac{\widetilde{C}_{s, t}(j)}{\widetilde{C}_{s, t+1}(j)} \frac{P_{t}}{P_{t+1}}
$$

Combining (11) with (7) one obtains

$$
E_{t}\left\{\Lambda_{t, t+1}(s, j)\right\}=\frac{1}{R_{t}}
$$

for each $s \in(-\infty, t]$ and $j \in[0,1]$. At the optimum the flow budget constraint (4) holds with equality in

\footnotetext{
${ }^{11}$ In particular, Ascari and Rankin (2007) demonstrate that this specification of preferences allows one to rule out a negative labor supply problem which may arise for older generations in models à la Yaari-Blanchard with leisure in the utility function when leisure is a normal good.
} 
each time period and the transversality condition precluding Ponzi's games must be verified:

$$
\lim _{T \rightarrow \infty} E_{t}\left\{(1-\lambda)^{T-t} \Lambda_{t, T}(s, j) A_{s, T}(j)\right\}=0
$$

where $\Lambda_{t, T}(s, j) \equiv \prod_{k=T+1}^{T} \Lambda_{k-1, k}(s, j)$ and $\Lambda_{t, t}(s, j) \equiv 1$. Iterating the budget constraint (4) forward, using (12), and imposing the transversality condition (13), one can derive the individual consumption function as: ${ }^{12}$

$$
P_{t} \widetilde{C}_{s, t}(j)=\chi\left[\begin{array}{c}
A_{s, t}(j)+H_{s, t}(j) \\
-\frac{1}{1-\gamma} E_{t} \sum_{T=t}^{\infty}(1-\lambda)^{T-t} \Lambda_{t, T}(s, j) \Psi_{s, T}(j)^{-\gamma} P_{T} V\left(N_{s, T}(j)\right)
\end{array}\right]
$$

where $\chi \equiv(1-\gamma)[1-\beta(1-\lambda)]$ is invariant both across time and across generations, the term $\Psi_{s, t}(j)$ $\equiv M_{s, t}(j) / P_{t} C_{s, t}(j)=\{\gamma /[(1-\gamma)(1-\lambda)]\}\left[R_{t} /\left(R_{t}-1\right)\right]$ is identical for all generations, and $H_{s, t}(j)$ is human wealth, defined as the expected present discounted value of future labor incomes and of profit shares net of taxes:

$$
H_{s, t}(j) \equiv E_{t} \sum_{T=t}^{\infty}(1-\lambda)^{T-t} \Lambda_{t, T}(s, j)\left(W_{s, T}(j) N_{s, T}(j)+Z_{s, T}(j)-T_{s, T}(j)\right)
$$

\subsubsection{Aggregation}

The aggregate value $X_{t}$ of a general economic variable $X_{s, t}(j)$ is obtained as a sum across cohorts:

$$
X_{t} \equiv \sum_{s=-\infty}^{t}\left(\int_{0}^{\lambda(1-\lambda)^{t-s}} X_{s, t}(j) d j\right)
$$

Aggregation of all generations alive at time $t$ yields the following expressions for aggregate non-human wealth, aggregate consumption, aggregate real money demand and aggregate labor supply, respectively:

$$
\begin{gathered}
\frac{B_{t+1}}{R_{t}}+M_{t}+Q_{t} K_{t+1}=A_{t}+W_{t} N_{t}+Z_{t}-T_{t}-P_{t} C_{t} \\
P_{t} \widetilde{C}_{t}=\chi\left[A_{t}+H_{t}-\frac{1}{1-\gamma} E_{t} \sum_{T=t}^{\infty}(1-\lambda)^{T-t} \Lambda_{t, T} \Psi_{T}^{-\gamma} P_{T} V\left(N_{T}\right)\right] \\
\frac{M_{t}}{P_{t}}=\frac{\gamma}{1-\gamma} \frac{R_{t}}{R_{t}-1} C_{t}, \\
\frac{W_{t}}{P_{t}}=\frac{1+u_{t}^{w}}{1-\gamma} \Psi_{t}^{-\gamma} V^{\prime}\left(N_{t}\right) .
\end{gathered}
$$

Combining equations (17) and (18) and using the definition of aggregate human wealth, $H_{t}(j) \equiv$

\footnotetext{
${ }^{12}$ See Appendix A for derivation.
} 
$E_{t} \sum_{T=t}^{\infty}(1-\lambda)^{T-t} \Lambda_{t, T}\left(W_{T} N_{T}+Z_{T}-T_{T}\right)$, one obtains the following dynamic equation for aggregate consumption: ${ }^{13}$

$$
P_{t} \widetilde{C}_{t}=\frac{1}{\beta} E_{t}\left\{\Lambda_{t, t+1} P_{t+1} \widetilde{C}_{t+1}\right\}+\frac{\lambda \chi}{\beta(1-\lambda)} E_{t}\left\{\Lambda_{t, t+1} A_{t+1}\right\}
$$

Equation (21) reveals that in the general case of finite lifetime $(\lambda>0)$, the time path of consumption is affected by the aggregate level of non-human wealth.

\section{$2.2 \quad$ Firms}

\subsubsection{Final Goods Firm}

The final good representative firm faces a CES production function given by $Y_{t}=\left(\int_{0}^{1} X_{t}(i)^{\frac{\varepsilon-1}{\varepsilon}} d i\right)^{\frac{\varepsilon}{\varepsilon-1}}$, where $Y_{t}$ denotes aggregate output and $X_{t}(i)$ is the quantity of intermediate good produced by intermediate goods firm $i$. Intratemporal profit maximization, taking as given the final good price $P_{t}$ and the prices of the intermediate goods $P_{t}(i)$, for all $i \in[0,1]$, yields the demand for each variety $i$ as a function of the relative price of $i$ and of total production, $X_{t}(i)=\left(P_{t}(i) / P_{t}\right)^{-\varepsilon} Y_{t}$. In addition, the zero profit condition implies that the price index is $P_{t}=\left(\int_{0}^{1} P_{t}(i)^{1-\varepsilon} d i\right)^{\frac{1}{1-\varepsilon}}$.

\subsubsection{Intermediate Goods Firm}

Each intermediate goods producer faces the following production function:

$$
Y_{t}(i)=\digamma_{t} K_{t}(i)^{\alpha} N_{t}(i)^{1-\alpha}
$$

where $\digamma_{t}$ is an exogenous technology parameter, and $K_{t}(i)$ and $N_{t}(i)$ represent the capital and labor services used by firm $i$, respectively. The labor input used by each producer is defined as a CES composite of individual consumer labor input:

$$
N_{t}(i)=\left(\sum_{s=-\infty}^{t} \int_{0}^{\lambda(1-\lambda)^{t-s}} N_{s, t}(i, j)^{\frac{\eta_{t}-1}{\eta_{t}}} d j\right)^{\frac{\eta_{t}}{\eta_{t}-1}}
$$

Aggregation across intermediate goods optimizing firms yields the labor market demand curve (2).

Following Calvo (1983), nominal price rigidity is modeled by allowing random intervals between price changes. Each period a firm adjusts its price with a constant probability $(1-\theta)$ and keeps its price fixed with probability $\theta$. The cost minimization condition requires that

$$
\frac{K_{t}(i)}{N_{t}(i)}=\frac{\alpha}{1-\alpha} \frac{W_{t}}{R_{t}^{k}}
$$

\footnotetext{
${ }^{13}$ See Appendix B for derivation.
} 
Real marginal cost, $M C_{t}$, is given by

$$
M C_{t}=\frac{\alpha^{-\alpha}(1-\alpha)^{\alpha-1}}{\digamma_{t}}\left(\frac{R_{t}^{k}}{P_{t}}\right)^{\alpha}\left(\frac{W_{t}}{P_{t}}\right)^{1-\alpha}
$$

thereby being identical across firms.

The optimal pricing decision of the firm $i$ revising its price in period $t$ is to choose the price $P_{t}(i)$ to maximize

$$
E_{t} \sum_{T=t}^{\infty} \theta^{T-t} \Lambda_{t, T} Y_{T}(i)\left(P_{t}(i)-P_{T} M C_{T}\right),
$$

subject to the sequence of demand constraints $\left\{Y_{T}(i)=X_{T}(i)=\left(P_{t}(i) / P_{T}\right)^{-\varepsilon} Y_{T}\right\}_{T=t}^{\infty}$. The first order condition for the optimal price is

$$
E_{t} \sum_{T=t}^{\infty} \theta^{T-t} \Lambda_{t, T} Y_{T} P_{T}^{\varepsilon}\left[P_{t}(i)-\left(1+\mu^{p}\right) P_{T} M C_{T}\right]=0
$$

where $\mu^{p}=1 /(\varepsilon-1)$ is the equilibrium net markup. From condition (27) it emerges that firms set their price equal to a markup over a weighted average of expected future nominal marginal costs. Finally, the price index follows a law of motion of the form:

$$
P_{t}=\left[\theta\left(P_{t-1}\right)^{1-\varepsilon}+(1-\theta) P_{t}(i)^{1-\varepsilon}\right]^{1 / 1-\varepsilon}
$$

\subsubsection{Capital Producers}

The representative capital producer employs investment (expressed in the same composite as the final good) and the existing capital stock to produce new capital goods, according to a standard CRS production function, $\phi\left(I_{t} / K_{t}\right) K_{t}$, where $\phi^{\prime}(\bullet)>0, \phi^{\prime \prime}(\bullet) \leq 0, \phi^{\prime}(\delta)=1, \phi(\delta)=\delta$, capturing convex adjustment costs. Hence, the capital accumulation equation is given by

$$
K_{t+1}=(1-\delta) K_{t}+\phi\left(\frac{I_{t}}{K_{t}}\right) K_{t}
$$

Profit maximization implies the following optimality condition:

$$
Q_{t} \phi^{\prime}\left(\frac{I_{t}}{K_{t}}\right)=P_{t}
$$




\subsection{The Monetary Authority}

The monetary authority controls the nominal interest rate, $r_{t} \equiv R_{t}-1$. Monetary policy is described in terms of a feedback rule where the instrument rate is set as an increasing function of the inflation rate. Specifically, the policy reaction function takes the following form: ${ }^{14}$

$$
\widetilde{r}_{t}=\rho_{r} \widetilde{r}_{t-1}+\left(1-\rho_{r}\right)\left(\phi_{\pi} \pi_{t}+\phi_{Y} \widehat{Y}_{t}\right)+\varepsilon_{t}^{r}
$$

where $\widetilde{r}_{t} \equiv r_{t}-r$ denotes the deviation of the nominal interest rate from its steady state level, $\pi_{t} \equiv$ $P_{t} / P_{t-1}-1$ is the rate of inflation between $t$ and $t-1, \widehat{Y}_{t} \equiv \log Y_{t}-\log Y$ is the $\log$-deviation of output from its steady state level, $\phi_{\pi}, \phi_{Y} \geq 0$ are parameters capturing the responsiveness of monetary policy to inflation and output, $\rho_{r} \in(0,1)$ is the parameter featuring a smoothing behavior of the central bank, and $\varepsilon_{t}^{R} \sim N\left(0, \sigma_{\varepsilon_{t}^{r}}^{2}\right)$ is an i.i.d. monetary disturbance.

\subsection{The Fiscal Authority}

The flow budget constraint of the government in nominal terms is given by

$$
\frac{B_{t+1}}{R_{t}}+M_{t}=B_{t}+M_{t-1}+P_{t} G_{t}-T_{t}
$$

where $G_{t}$ denotes real government spending for final goods. The fiscal authority has three policy instruments: bonds, government spending, and net lump sum taxes, of which only two can be chosen freely and the remaining follows residually from the government's sequential budget constraint.

The budget constraint (32) can be written in real terms as

$$
\frac{l_{t+1}}{R_{t}}=\frac{l_{t}}{1+\pi_{t}}+G_{t}-\tau_{t}-\frac{R_{t}-1}{R_{t}} m_{t}
$$

where $l_{t} \equiv\left(B_{t}+M_{t-1}\right) / P_{t-1}$ denote total real government liabilities outstanding at the beginning of period $t$ in units of $t-1$ final goods, $\tau_{t} \equiv T_{t} / P_{t}$ real tax collections, and $m_{t} \equiv M_{t} / P_{t}$ real money balances.

Our analysis focuses on two alternative fiscal policy rules: $(i)$ a debt-based tax rule of the Leeper (1991)-style; (ii) a balanced-budget rule allowing for bounded deficits or surpluses, of the kind presented by Schmitt-Grohé and Uribe (2000). Both rules are extended to incorporate a cyclical component in the spirit of Taylor $(2000 \mathrm{a}, 2000 \mathrm{~b}){ }^{15}$

\footnotetext{
${ }^{14}$ See, e.g., Clarida, Galí and Gertler (1998, 2000), Judd and Rudebusch (1998), Taylor (1999b), Gerlach and Schnabel (2000), Orphanides (2001, 2003), and Sauer and Sturm (2007) for empirical evidence on Taylor-type rules.

${ }^{15}$ Ascari and Rankin (2007) analyze the issue of fiscal policy effectiveness in a New Keynesian model with oLG assuming a real government debt targeting regime.
} 


\subsubsection{Debt-based Tax Rule}

Under a debt-based regime, fiscal policy is assumed to be conducted according to the following feedback tax rule:

$$
\widehat{\tau}_{t}=\tau_{l} \widehat{l}_{t}+\tau_{Y} \widehat{Y}_{t}
$$

where $\widehat{\tau}_{t} \equiv\left(\tau_{t}-\tau\right) / Y$ and $\widehat{l}_{t} \equiv\left(l_{t}-l\right) / Y$ denote, respectively, the fluctuations of real taxes and government liabilities, both measured in units of steady-state output, and $\tau_{l}, \tau_{Y} \geq 0$ are fiscal policy parameters. Such a specification takes into account both a debt stabilization motive (of the kind described by Leeper, 1991), capturing the structural component of fiscal policy, and an output stabilization motive, reflecting the cyclical component. ${ }^{16}$

\subsubsection{Balanced-budget Rule}

As an alternative fiscal regime we consider a balanced-budget rule allowing for bounded deficits or surpluses. As emphasized by Schmitt-Grohé and Uribe (2000), this fiscal rule is arguably more realistic than a period-by period balanced budget requirement. In addition, it is in the spirit of the Maastricht Treaty and the Stability and Growth Pact, which require country specific medium term objectives which range from a $1 \%$ deficit to a close to balance or in surplus position, guaranteeing a sufficient margin below the reference value of $3 \%$ of GDP for the general government deficit.

The nominal fiscal deficit, $D_{t}$, is defined as government expenditures and interest payments on the outstanding public debt net of tax revenues:

$$
D_{t} \equiv P_{t} G_{t}+\left(R_{t-1}-1\right) \frac{B_{t}}{R_{t-1}}-T_{t}
$$

Using (35) into the government's flow budget constraint (32) yields

$$
\frac{B_{t+1}}{R_{t}}+M_{t}=\frac{B_{t}}{R_{t-1}}+M_{t-1}+D_{t}
$$

We assume that fiscal policy is described in terms of a feedback rule in the real deficit, incorporating both an output stabilization motive and a smoothing component. ${ }^{17}$ In particular, the fiscal rule takes the following form:

$$
d_{t}=\rho_{d} d_{t-1}+\left(1-\rho_{d}\right) \delta_{Y} \widehat{Y}_{t}+\varepsilon_{t}^{d}
$$

where $d_{t} \equiv\left(D_{t} / P_{t}\right) / Y$ indicates the real deficit, measured in units of steady-state output, $\delta_{Y} \leq 0$ is a

\footnotetext{
${ }^{16}$ The so-called 'Taylor fiscal rules', featuring both 'active' and 'passive' components, are the object of recent empirical contributions. See, for instance, Galí and Perotti (2003), and Favero and Monacelli (2003, 2005).

${ }^{17}$ Schmitt-Grohé and Uribe (2000) instead assume exogenous 'secondary' deficits, without inertia.
} 
fiscal policy parameter, $\rho_{d} \in(0,1)$ is a parameter measuring the persistence of budget deficit dynamics shown in the data, and $\varepsilon_{t}^{d} \sim N\left(0, \sigma_{\varepsilon^{d}}^{2}\right)$ is an i.i.d. fiscal policy shock.

\subsection{Market Clearing}

Factor and good markets must be in equilibrium, so that the following equalities hold at all times: $N_{t}=\int_{0}^{1} N_{t}(i) d i, K_{t}=\int_{0}^{1} K_{t}(i) d i, Y_{t}(i)=X_{t}(i)$, for all $i \in[0,1]$, and

$$
Y_{t}=C_{t}+I_{t}+G_{t}
$$

\section{Calibration}

The implications of the foregoing framework are examined by computing a log-linearized version of the equilibrium conditions around a non-stochastic steady state with zero inflation. ${ }^{18}$ The log-linearized model is solved in its state-space representation by applying the Klein (2000) algorithm. ${ }^{19}$ We parameterize the model on euro area quarterly data for the period 1970Q1-2003Q4. ${ }^{20}$ The baseline calibration is reported in Table 1.

The shares of steady-state consumption and private investment in total output are set consistently with their observed sample averages, 0.2. We set the annual steady state public debt to GDP ratio at $60 \%$, according to the Maastricht criterion. The observed annual money velocity is 3.7 , using the monetary aggregate M1. We set the steady state real interest rate equal to $4 \%$ per annum, as in Smets and Wouters (2003). We assign a value of 0.015 to the probability of death between two consecutive periods, as in Leith and Wren-Lewis (2000).

The function characterizing the agents' dis-utility of labor is assumed to be

$$
V\left(N_{t}\right) \equiv \frac{N_{t}^{1+\varphi}}{1+\varphi}
$$

where $\varphi>0$ represents the inverse of the (Frisch) elasticity of labor supply with respect to the real wage. We set $\varphi$ equal to 0.47, as in Benigno and Benigno (2006). Furthermore, we calibrate the steady state fraction of time in employment to be $1 / 3$, according to the standard eight-hours working day.

The probability of maintaining prices fixed between two consecutive quarters for firms subject to nominal rigidities is set equal to 0.75 , that is consistent with the estimates obtained by Galí, Gertler and López-Salido (2001) for the euro area. Following Smets and Wouters (2003), we set the annual

\footnotetext{
${ }^{18}$ See Appendix $\mathrm{C}$ for details.

${ }^{19}$ See Appendix D.

${ }^{20}$ The data are obtained from the database constructed by Fagan, Henry and Mestre (2005).
} 
depreciation rate, $\delta$, equal to $10 \%$ per annum and the elasticity of output with respect to capital, $\alpha$, equal to 0.3. Following King and Watson (1996), the elasticity of investment with respect to asset prices, $\eta$, is set equal to unity. Values of all remaining parameters are set according to the steady state relations and are reported in Table 1.

We assume that government expenditure follows a univariate autoregressive process given by

$$
\widehat{G}_{t}=\rho_{G} \widehat{G}_{t-1}+\varepsilon_{t}^{G},
$$

where $\widehat{G}_{t} \equiv \frac{G_{t}-G}{Y}$. The estimated first-order autocorrelation and the standard deviation of the innovation are $\rho_{G}=0.966$ and $\sigma_{\varepsilon^{G}}=0.001$, respectively. The technology shock is also assumed to follow a univariate autoregressive process,

$$
\widehat{\digamma}_{t}=\rho_{\digamma} \widehat{\digamma}_{t-1}+\varepsilon_{t}^{\digamma}
$$

where $\widehat{\digamma}_{t} \equiv \log \digamma_{t}-\log \digamma$. We fit the stochastic process (41) empirically using the standard Solow residual and obtain $\rho_{\digamma}=0.958$ and $\sigma_{\varepsilon \digamma}=0.005$. Following Smets and Wouters (2003), the wage markup is assumed to be a white noise. We set the standard deviations of the wage markup and the monetary policy shocks equal to Smets and Wouters' estimates, $\sigma_{u^{w}}=0.003$ and $\sigma_{\varepsilon^{r}}=0.001$. Finally, the baseline calibration of equations (31) and (37) sets $\rho^{r}, \rho^{d}=0.9$, consistently with a realistic high degree of inertia displayed by monetary and fiscal rules.

\section{$4 \quad$ Fiscal Policy and Equilibrium Dynamics}

The main feature of the present model is that it exhibits wealth effects on aggregate demand that make the LM relation and the dynamics for both government liabilities and asset prices not recursive to the equilibrium system. ${ }^{21}$ This generates a non-trivial interaction between monetary and fiscal policy. On the one hand, fiscal policy affects the evolution of aggregate demand since public debt is net wealth for the living generations, thereby influencing inflation dynamics. On the other hand, monetary policy affects debt service through its decisions on the nominal interest rate, hence modifying the dynamics of government liabilities.

For each fiscal rule, we first investigate the issue of rational expectations equilibrium determinacy to identify the range of policy parameters ruling out sunspots and instabilities; ${ }^{22}$ then we examine impulse

\footnotetext{
${ }^{21}$ By contrast, in the standard New Keynesian representative agent setup, real financial wealth does not affect consumption dynamics and monetary policy influences consumption only through the effects produced on the current and future shortterm real interest rates.

${ }^{22} \mathrm{~A}$ rational expectations equilibrium is (locally) determined if and only if there are unique bounded sequences for all endogenous variables of the model in periods $t \geq 0$, given the bounded exogenous disturbances processes. See Woodford (2003). As we shall see, nesting multiple numerical loops, conditions for determinacy of the present model are checked for different combinations of the policy parameters in the relevant interval with an increment of 0.01 . Each time that the model
} 
response functions to fiscal shocks.

\subsection{Debt-based Tax Rule}

Following Woodford (1998, 2001, 2003), fiscal policy is 'passive' (or 'locally Ricardian') if and only if the dynamics of real government liabilities implied by the tax rule are bounded for any bounded sequences for the other endogenous variables and for the exogenous disturbances. According to this definition, the tax rule (34) is passive (active) if and only if $\left|(1+r)\left(1-\tau_{l}\right)\right|<(>) 1 .^{23}$ As in Woodford (2003), we focus on rules in which $\tau_{l} \leq 1$. Thus, our calibration implies that for a passive (active) fiscal policy $\tau_{l}$ must be larger (smaller) than 0.01 .

Figure 1 shows the regions of determinacy of equilibrium under the tax rule for different combinations of fiscal and monetary policy parameters. Panel A reveals that a passive fiscal policy regime is compatible with equilibrium determinacy when combined with a sufficiently active monetary policy. On the other hand, an active fiscal policy requires a more accommodating monetary policy. As it emerges from panel $\mathrm{B}$, when fiscal policy is passive, the Taylor principle, according to which the long-run response of the nominal interest rate to increases in inflation should be more than one-to-one $\left(\phi_{\pi}>1\right)$, might not be sufficient to achieve equilibrium uniqueness. Indeterminacy is likely to prevail under a high responsiveness of monetary policy to the fluctuations in output. In panels $\mathrm{C}$ and $\mathrm{D}$ we plot determinacy regions in the space of the fiscal policy parameters $\left(\tau_{l}, \tau_{Y}\right)$ under an active and a passive monetary policy conduct, respectively. When monetary policy is active, the more countercyclical the fiscal policy is, the higher the reactivity of taxes to government liabilities must be in order to ensure equilibrium determinacy. By contrast, under a low reactivity of the fiscal burden to government liabilities and passive monetary policy, equilibrium uniqueness is more likely to be verified under a countercyclical fiscal policy.

Let now examine the responses of the main variables of the model to a positive unit shock in government spending under two alternative fiscal-monetary policy regimes (Figure 2). As in Woodford (2003), the size of the fiscal shock is normalized to a one percent of steady-state output.

Consider first the case of a passive fiscal policy combined with an active monetary policy (Figure $2(\mathrm{~A}))$. In particular, let assume $\tau_{l}=0.1, \tau_{Y}=0.5, \phi_{\pi}=1.5, \phi_{Y}=0.125$, i.e., the values of a standard Taylor rule. The output dynamics display an intertemporal trade-off: the fiscal expansion boosts economic activity in the short run but generates a persistent negative effect in the medium run, due to the crowdingout in both private consumption and private investment.

Consider now the case of an active fiscal rule coupled with with a passive interest rate rule (Figure 2(B)). Specifically, let set $\tau_{l}=0, \tau_{Y}=0.5, \phi_{\pi}=\phi_{Y}=0$, implying a pegged interest rate. When the tax satisfied conditions for determinacy a dark point is plotted.

${ }^{23}$ For details see Appendix E. 
rule does not ensure a convergent pattern for real government liabilities for any bounded sequence of the other endogenous variables, a government spending shock causes output, consumption, investment, capital and asset prices to increase persistently above their initial steady state values. These expansionary effects are sustained by both the passive behavior of monetary policy, implying cumulative decreases in the real interest rate, and the wealth effects on aggregate demand, that are amplified by the 'non-Ricardian' fiscal policy. As a result, in equilibrium, the inflationary effects necessary to prevent an explosive dynamics for real government liabilities are about five times larger than in the previous fiscal-monetary regime.

\subsection{Balanced-budget Rule}

The evolution of real government liabilities under a balanced-budget rule allowing for temporary fiscal deficits of the type described by (37) exhibits a unit root. ${ }^{24}$ Therefore a balanced-budget rule cannot be strictly classified according to the active/passive dichotomy in Woodford's (2003) sense and deserves a separate analysis. ${ }^{25}$

Figure 3 shows that in our framework with wealth effects this particular fiscal regime is compatible with a larger class of interest rate rules of Taylor's type by enlarging the parameter space under which determinacy is guaranteed (see panel B) ${ }^{26}$, unless fiscal policy is too much countercyclical (see panel A). In particular, under passive monetary policies, where the nominal interest rate responds less than proportionally to inflation changes, or under interest rate pegging rules, the system is not characterized by sunspot fluctuations or instabilities as in the standard infinite horizon framework. Under balanced-budget requirements, intergenerational wealth effects work as 'automatic stabilizers', not forcing necessarily the central bank to implement aggressive interest rate rules. Hence, a remarkable advantage of our set up is that it enables one to study the impact of fiscal policy shocks under a wider range of monetary policy rules.

Figure 4 plots the impulse response functions to a unit shock to government spending under both active $\left(\phi_{\pi}>1\right)$ and passive $\left(\phi_{\pi}<1\right)$ interest rate rules, respectively. Analyzing the impulse responses under the alternative monetary policy rules, it emerges that the responses of the variables to the shocks are critically affected by the conduct of monetary policy. Under an active monetary policy (Figure 4(A)), assuming $\phi_{\pi}=1.5, \phi_{Y}=0.125$ and $\delta_{Y}=-0.5$, the dynamics are similar to those obtained in the case of a passive tax rule. Output increases on impact, but declines thereafter below the long run equilibrium, returning very slowly to the steady state. Inflation increases on impact while consumption, capital, investment

\footnotetext{
${ }^{24}$ See equation (A.32) in Appendix C.

${ }^{25}$ Broadly speaking, as emphasized by Schmitt-Grohé and Uribe (2000), the balanced-budget rule could be considered 'passive' in Leeper (1991)'s sense, since it implies that taxes are an increasing function of the stock of public debt.

${ }^{26}$ An analytical proof can be found in Annicchiarico and Piergallini (2006) in a simplified DSGE framework with no capital accumulation and real money balances.
} 
and asset prices initially decrease and slowly converge back to the steady state. Conversely, when the monetary rule is passive (Figure $4(\mathrm{~B})$ ), assuming $\phi_{\pi}=0.5, \phi_{Y}=0.125$ and $\delta_{Y}=-0.5$, the patterns are distinctly different. On impact there is an increase in output, capital, investment, consumption and asset prices, supported by the accommodative behavior of the monetary authority. ${ }^{27}$ However, the initial increase in inflation is almost two times larger than in the active monetary policy case.

\section{Macroeconomic Stability}

Let now explore the performance of alternative fiscal rules or different combinations of monetary and fiscal rules by using Montecarlo experiments. We draw from a random generator a finite set of innovation sequences $\left(\varepsilon_{t}^{G}, \varepsilon_{t}^{r}, \varepsilon_{t}^{\digamma}, \varepsilon_{t}^{u^{w}}\right)$ for a sample period of 200 quarters. All values reported in Tables 2-4 represent mean values of the standard deviations of inflation, output, the nominal interest rate and asset prices over 1000 replications of the simulation experiment. The magnitudes shown in the Tables are expressed in percentage points.

The first simulation exercise reported in Table 2 investigates the performance of monetary and fiscal policies under feedback tax rules ensuring the convergence of government liabilities dynamics for any bounded paths for the remaining endogenous variables. The results indicate that higher values for the monetary policy inflation coefficient $\phi_{\pi}$ lead to lower standard deviations for the inflation rate. Moreover, an interest rate rule featuring a response to output entails in most cases a higher variability in all variables of interest. This conclusion reinforces the results developed by McCallum (2001), and Schmitt-Grohé and Uribe (2007).

Table 3 reports simulation results under the assumption that fiscal policy is conducted according to an active tax rule. The results suggest that when the stability of government liabilities is not guaranteed by fiscal authorities, an interest rate peg rule is predicted to perform better, in terms of inflation stabilization, than feedback interest rate rules à la Taylor. Intuitively, a feedback monetary rule reacting to inflation dramatically worsens the dynamics of government liabilities when budgetary policies are potentially unsustainable, thereby pinning down a higher inflation rate necessary to reduce the real value of public debt. Hence, the well-known revaluation mechanism depicted by the 'fiscal theory of the price level' is fully at work. In addition, large values for $\tau_{Y}$, capturing the response of the tax rule to output, entail excessive variability.

Table 4 summarizes simulation results under balanced-budget requirements. As emphasized in the previous sections, in our OLG framework this fiscal regime permits to compare the performance of both

\footnotetext{
${ }^{27}$ This theoretical result is compatible with the empirical findings of Blanchard and Perotti (2002), showing an increase in private consumption in response to a positive government spending shock.
} 
active and passive monetary policies, since the prospects for determinacy of rational expectations equilibrium are enlarged. Active interest rate rules that do not feature an output stabilization motive imply a lower variability for inflation, but they are likely to entail a higher variability for both output and asset prices. Furthermore, the results support the view that strong responses of fiscal policy to output might be undesirable.

\section{Conclusions}

In this paper we have presented a dynamic stochastic general equilibrium model with price stickiness and capital accumulation, extended to include overlapping generations. An important feature of our economy with finitely-lived individuals is that the dynamics for government liabilities and asset prices as well as the LM relation significantly affect the monetary and fiscal policy transmission mechanisms, because wealth effects do influence aggregate consumption dynamics. The general framework presented in the paper is flexible enough for analyzing the effects of different fiscal policy rules, and their interaction with monetary policy, in terms of macroeconomic stability and price developments. The analysis of the performance of debt-based tax rules and balanced-budget rules allowing for temporary deficits shows that the positive effect on economic activity generated by fiscal expansions is likely to be significantly reversed in the medium run. An interesting insight of our set-up is that the balanced-budget rule is able to enlarge the determinacy space under feedback interest rate rules. This allows the evaluation of the effects of fiscal policy under both active and passive monetary policies. In this respect, we have shown that the dynamics generated by fiscal shocks are critically influenced by the monetary policy regime. On the one hand, fiscal policies aimed at balancing the budget are compatible with passive monetary policies; on the other hand, active monetary policies in conjunction with a balanced budget rule deliver a high degree of price stability, at the expense of output volatility. Finally, an important implication of the results found is that controlling for monetary policy might be essential for an empirical characterization of the effects of fiscal shocks. In other words, results of the empirical literature on the effect of fiscal policies on macroeconomic variables could have been negatively influenced by the exclusion of the interaction between monetary and fiscal policies. 


\section{Appendixes}

\section{Appendix A: Individual Consumption}

Combining (12) with (8) we obtain

$$
E_{t}\left\{\Lambda_{t, t+1}(s, j) R_{t}\right\}=E_{t}\left\{\Lambda_{t, t+1}(s, j) \frac{(1-\delta) Q_{t+1}+R_{t+1}^{k}}{Q_{t}}\right\}=1
$$

Using (A.1) we can write

$$
\begin{aligned}
& \frac{B_{s, t+1}(j)}{R_{t}}+M_{s, t}(j)+Q_{t} K_{s, t+1}(j) \\
= & E_{t}\left\{\Lambda_{t, t+1}(s, j)\left[B_{s, t+1}(j)+M_{s, t}(j)+R_{t} Q_{t} K_{s, t+1}(j)\right]\right\}+\frac{R_{t}-1}{R_{t}} M_{s, t}(j) \\
= & E_{t}\left\{\Lambda_{t, t+1}(s, j)\left[B_{s, t+1}(j)+M_{s, t}(j)+\left(Q_{t+1}(1-\delta)+R_{t+1}^{k}\right) K_{s, t+1}(j)\right]\right\}+\frac{R_{t}-1}{R_{t}} M_{s, t}(j) .
\end{aligned}
$$

Thus, the individual flow budget constraint can be written as

$$
\begin{aligned}
& P_{t} C_{s, t}(j)+(1-\lambda) \frac{R_{t}-1}{R_{t}} M_{s, t}(j)+(1-\lambda) E_{t}\left\{\Lambda_{t, t+1}(s, j) A_{s, t+1}(j)\right\} \\
\leq & A_{s, t}(j)+W_{s, t}(j) N_{s, t}(j)+Z_{s, t}(j)-T_{s, t}(j),
\end{aligned}
$$

where

$$
A_{s, t}(j) \equiv B_{s, t}(j)+M_{s, t-1}(j)+\left[Q_{t}(1-\delta)+R_{t}^{k}\right] K_{s, t}(j) .
$$

Note that

$$
\begin{aligned}
& C_{s, t}(j)+(1-\lambda) \frac{R_{t}-1}{R_{t}} \frac{M_{s, t}(j)}{P_{t}} \\
= & \frac{1}{1-\gamma} C_{s, t}(j) \\
= & \frac{1}{1-\gamma} \widetilde{C}_{s, t}(j)+\frac{1}{1-\gamma}\left(\frac{P_{t} C_{s, t}(j)}{M_{s, t}(j)}\right)^{\gamma} V\left(N_{s, t}(j)\right) .
\end{aligned}
$$

Thus, the flow budget constraint can be re-written as

$$
\begin{aligned}
& \frac{1}{1-\gamma} P_{t} \widetilde{C}_{s, t}(j)+(1-\lambda) E_{t}\left\{\Lambda_{t, t+1}(s, j) A_{s, t+1}(j)\right\} \\
\leq & A_{s, t}(j)+W_{s, t}(j) N_{s, t}(j)+Z_{s, t}(j)-T_{s, t}(j)-\frac{1}{1-\gamma}\left(\frac{P_{t} C_{s, t}(j)}{M_{s, t}(j)}\right)^{\gamma} P_{t} V\left(N_{s, t}(j)\right) .
\end{aligned}
$$

From (A.6), imposing the transversality condition we obtain the intertemporal budget constraint:

$$
\begin{aligned}
& \frac{1}{1-\gamma} E_{t} \sum_{T=t}^{\infty}(1-\lambda)^{T-t} \Lambda_{t, T}(s, j) P_{T} \widetilde{C}_{s, T}(j) \\
\leq & A_{s, t}(j)+E_{t} \sum_{T=t}^{\infty}(1-\lambda)^{T-t} \Lambda_{t, T}(s, j)\left(W_{s, T}(j) N_{s, T}(j)+Z_{s, T}(j)-T_{s, T}(j)\right) \\
& \left.-\frac{1}{1-\gamma} E_{t} \sum_{T=t}^{\infty}(1-\lambda)^{T-t} \Lambda_{t, T}(s, j)\left(\frac{P_{T} C_{s, T}(j)}{M_{s, T}(j)}\right)^{\gamma} P_{T} V\left(N_{s, T}(j)\right)\right] .
\end{aligned}
$$


Using the fact that

$$
E_{t}\left\{\Lambda_{t, T}(s, j) P_{T} \widetilde{C}_{s, T}(j)\right\}=\beta^{T-t} P_{t} \widetilde{C}_{s, t}(j)
$$

into equation (A.7) (which in the optimum holds with equality), one obtains equation (14) in the main text.

\section{Appendix B: The Dynamic Equation for Aggregate Consumption}

Using (12) we can write

$$
\frac{B_{t+1}}{R_{t}}+M_{t}+Q_{t} K_{t+1}=E_{t}\left\{\Lambda_{t, t+1}\left[B_{t+1}+M_{t}+\left(Q_{t+1}(1-\delta)+R_{t+1}^{k}\right) K_{t+1}\right]\right\}+\frac{R_{t}-1}{R_{t}} M_{t} .
$$

Thus, the aggregate budget constraint can also be written as

$$
E_{t}\left\{\Lambda_{t, t+1} A_{t+1}\right\}+P_{t} C_{t}+\frac{R_{t}-1}{R_{t}} M_{t}=A_{t}+W_{t} N_{t}+Z_{t}-T_{t}
$$

where $A_{t}$ denotes aggregate non-human wealth at the beginning of period $t$, defined as

$$
A_{t} \equiv B_{t}+M_{t-1}+\left(Q_{t}(1-\delta)+R_{t}^{k}\right) K_{t}
$$

Note that

$$
P_{t} C_{t}+\frac{R_{t}-1}{R_{t}} M_{t}=\frac{1}{1-\gamma} P_{t} C_{t} .
$$

Substituting (A.10) into (18) and using (A.12) one obtains

$$
P_{t} \widetilde{C}_{t}=\chi\left[\begin{array}{c}
E_{t}\left\{\Lambda_{t, t+1} A_{t+1}\right\}+\frac{1}{1-\gamma} P_{t} C_{t}+E_{t} \sum_{T=t+1}^{\infty}(1-\lambda)^{T-t} \Lambda_{t, T} \Omega_{T} \\
-\frac{1}{1-\gamma} E_{t} \sum_{T=t}^{\infty}(1-\lambda)^{T-t} \Lambda_{t, T} \Psi_{T}^{\gamma} P_{T} V\left(N_{T}\right)
\end{array}\right]
$$

where $\Omega_{t}=W_{t} N_{t}+Z_{t}-T_{t}$. Leading (18) one period forward yields

$$
P_{t+1} \widetilde{C}_{t+1}=\chi\left[\begin{array}{c}
A_{t+1}+E_{t+1} \sum_{T=t+1}^{\infty}(1-\lambda)^{T-(t+1)} \Lambda_{t+1, T} \Omega_{T} \\
-\frac{1}{1-\gamma} E_{t+1} \sum_{T=t}^{\infty}(1-\lambda)^{T-(t+1)} \Lambda_{t+1, T} \Psi_{T}^{\gamma} P_{T} V\left(N_{T}\right)
\end{array}\right] .
$$


Multiplying both sides by $\Lambda_{t, t+1}(1-\lambda)$ and taking expectations:

$$
\begin{aligned}
& (1-\lambda) E_{t}\left\{\Lambda_{t, t+1} P_{t+1} \widetilde{C}_{t+1}\right\} \\
= & \chi\left[\begin{array}{c}
(1-\lambda) E_{t}\left\{\Lambda_{t, t+1} A_{t+1}\right\}+E_{t} \sum_{T=t+1}^{\infty}(1-\lambda)^{T-t} \Lambda_{t, T} \Omega_{T} \\
-\frac{1}{1-\gamma} E_{t} \sum_{T=t+1}^{\infty}(1-\lambda)^{T-t} \Lambda_{t, T} \Psi_{T}^{\gamma} P_{T} V\left(N_{T}\right)
\end{array}\right] .
\end{aligned}
$$

Solving (A.15) for $E_{t} \sum_{T=t+1}^{\infty}(1-\lambda)^{T-t} \Lambda_{t, T} \Omega_{T}$, using $\chi \equiv(1-\gamma)[1-\beta(1-\lambda)]$, and substituting into (A.13), one obtains

$$
\begin{aligned}
& P_{t} \widetilde{C}_{t}=(1-\gamma)[1-\beta(1-\lambda)]\left[\begin{array}{c}
E_{t}\left\{\Lambda_{t, t+1} A_{t+1}\right\}-(1-\lambda) E_{t}\left\{\Lambda_{t, t+1} A_{t+1}\right\} \\
+\frac{1}{1-\gamma} P_{t}\left(C_{t}-\Psi_{t}^{\gamma} V\left(N_{t}\right)\right)
\end{array}\right] \\
& +(1-\lambda) E_{t}\left\{\Lambda_{t, t+1} P_{t+1} \widetilde{C}_{t+1}\right\} .
\end{aligned}
$$

Simplifying, (A.16) becomes

$$
P_{t} \widetilde{C}_{t}=(1-\gamma)[1-\beta(1-\lambda)]\left[\lambda E_{t}\left\{\Lambda_{t, t+1} A_{t+1}\right\}+\frac{1}{1-\gamma} P_{t} \widetilde{C}_{t}\right]+(1-\lambda) E_{t}\left\{\Lambda_{t, t+1} P_{t+1} \widetilde{C}_{t+1}\right\}
$$

Rearranging (A.17), we obtain the dynamic equation for aggregate adjusted consumption,

$$
P_{t} \widetilde{C}_{t}=\frac{1}{\beta} E_{t}\left\{\Lambda_{t, t+1} P_{t+1} \widetilde{C}_{t+1}\right\}+\frac{\lambda(1-\gamma)[1-\beta(1-\lambda)]}{\beta(1-\lambda)} E_{t}\left\{\Lambda_{t, t+1} A_{t+1}\right\}
$$

which is equation (21) in the main text.

\section{Appendix C: Linearized Equilibrium Conditions}

This Appendix performs a first-order log-linear approximation of the global system around a nonstochastic steady state characterized by zero inflation and positive public debt. In general, we let $\widehat{X}_{t} \equiv \log X_{t}-\log X$ be the log-deviation of a given economic variable $X_{t}$ from its steady state value $X$.

On the demand-side, the log-linear version of the dynamic equation for aggregate adjusted consumption (21) is given by

$$
\widehat{\widetilde{C}}_{t}=-\left(\widetilde{r}_{t}-\frac{1}{1+\omega} E_{t}\left\{\pi_{t+1}\right\}\right)+\frac{1}{1+\omega} E_{t}\left\{\widehat{\widetilde{C}}_{t+1}\right\}+\frac{\omega}{1+\omega} \widehat{a}_{t+1}
$$


where $a_{t} \equiv \frac{A_{t}}{P_{t-1}}$ and $\omega \equiv \beta R-1=\frac{\lambda \chi}{(1-\lambda)} \frac{a}{\widetilde{C}}$. The aggregate real financial wealth approximates to

$$
\widehat{a}_{t+1} \equiv s_{a}^{-1} \widehat{l}_{t+1}+R s_{a}^{-1} s_{K}\left(\widetilde{r}_{t}+\widehat{q}_{t}+\widehat{K}_{t+1}\right)
$$

where $q_{t} \equiv \frac{Q_{t}}{P_{t}}, s_{a} \equiv \frac{a}{Y}, s_{K} \equiv \frac{K}{Y}=\frac{\left(\frac{I}{Y}\right)}{\delta}=\frac{\alpha}{(r+\delta)\left(1+u^{p}\right)}$. Aggregate adjusted consumption approximates to

$$
\widehat{\widetilde{C}}_{t} \equiv \frac{C}{\widetilde{C}} \widehat{C}_{t}-\frac{\gamma}{r}\left(\frac{C}{\widetilde{C}}-1\right) \widetilde{r}_{t}-(1+\varphi)\left(\frac{C}{\widetilde{C}}-1\right) \widehat{N}_{t}
$$

where $\varphi \equiv V^{\prime \prime}(N) \frac{N}{V \prime(N)}$ is the inverse of the Frisch elasticity of labor supply, $\frac{C}{\widetilde{C}} \equiv \frac{C}{C-\Psi^{-\gamma} \frac{N^{1+\varphi}}{1+\varphi}}=$ $\frac{1}{1-\Psi^{-\gamma}\left(\frac{N}{Y}\right)\left(\frac{Y}{C}\right) \frac{N \varphi}{1+\varphi}}$, and $\frac{N}{Y}=\frac{(1-\alpha)\left(\frac{1}{1+u^{p}}\right)}{\frac{1+u^{w}}{1-\gamma} \Psi^{-\gamma} N^{\varphi}}$. The equation describing asset prices dynamics can be derived as

$$
\widehat{q}_{t}=\frac{1}{R}(1-\delta) E_{t}\left\{\widehat{q}_{t+1}\right\}+\left[1-\frac{1}{R}(1-\delta)\right] E_{t}\left\{\widehat{r}_{t+1}^{k}\right\}-\left(\widetilde{r}_{t}-E_{t}\left\{\pi_{t+1}\right\}\right),
$$

where $r_{t}^{k} \equiv \frac{R_{t}^{k}}{P_{t}}$. The log-linearized equation for investment demand is

$$
\widehat{I}_{t}-\widehat{K}_{t}=\eta \widehat{q}_{t}
$$

where $\eta \equiv-\phi^{\prime \prime}\left(\frac{I}{K}\right) \frac{\phi^{\prime}\left(\frac{I}{K}\right)}{\frac{I}{K}}$. From (19), one can derive the LM relation as

$$
\widehat{m}_{t}=\widehat{C}_{t}-\frac{1}{R-1} \widetilde{r}_{t}
$$

where $m_{t} \equiv \frac{M_{t}}{P_{t}}$. The labor supply equation (20) can be expressed as

$$
\widehat{w}_{t}=\varphi \widehat{N}_{t}+\frac{\gamma}{R-1} \widetilde{r}_{t}+u_{t}^{w}
$$

where $w_{t} \equiv \frac{W_{t}}{P_{t}}$.

On the supply-side, the log-linear approximations to the optimal price setting equation (27) and the definition of price index (28) yield

$$
\pi_{t}=\frac{1}{R} E_{t}\left\{\pi_{t+1}\right\}+\kappa \widehat{M C}_{t}
$$

where $\kappa \equiv \frac{(1-\theta)(R-\theta)}{R \theta}$, and

$$
\begin{aligned}
\widehat{M C}_{t} & =\widehat{w}_{t}-\left(\widehat{Y}_{t}-\widehat{N}_{t}\right) \\
& =\widehat{r}_{t}^{k}-\left(\widehat{Y}_{t}-\widehat{K}_{t}\right)
\end{aligned}
$$


In addition, the aggregate production function can be approximated as

$$
\widehat{Y}_{t}=\widehat{\digamma}_{t}+\alpha \widehat{K}_{t}+(1-\alpha) \widehat{N}_{t} .
$$

The law of motion of capital (29) becomes

$$
\widehat{K}_{t+1}=\delta \widehat{I}_{t}+(1-\delta) \widehat{K}_{t}
$$

Market clearing in the goods' market implies

$$
\widehat{Y}_{t}=s_{C} \widehat{C}_{t}+s_{I} \widehat{I}_{t}+\widehat{G}_{t},
$$

where $s_{C} \equiv \frac{C}{Y}, s_{I} \equiv \frac{I}{Y}$, and $\widehat{G}_{t} \equiv \frac{G_{t}-G}{Y}$.

On the public sector-side, the log-linear version of the evolution of government liabilities (33) is given by

$$
\widehat{l}_{t+1}=R\left(\widehat{l}_{t}-\frac{d}{Y} \pi_{t}+\widehat{G}_{t}-\widehat{\tau}_{t}\right)+s_{b} \widetilde{r}_{t}-(R-1) s_{m} \widehat{m}_{t},
$$

where $s_{b} \equiv \frac{B}{P Y}$ and $s_{m} \equiv \frac{m}{Y}$.

Under the balanced-budget rule, equation (36) can be approximated as

$$
\widehat{l}_{t+1}=\widehat{l}_{t}+s_{b}\left(\widetilde{r}_{t}-\widetilde{r}_{t-1}-\pi_{t}\right)-r s_{m}\left(\widehat{m}_{t}-\widehat{m}_{t-1}\right)-R s_{m} \pi_{t}+R d_{t} .
$$

\section{Appendix D: Model Solution}

The log-linearized model can be written in matrix form as follows:

$$
\left[\begin{array}{cc}
A_{11} & A_{12} \\
n_{F} \times n_{F} & n_{F} \times n_{S} \\
A_{21} & A_{22} \\
n_{S} \times n_{F} & n_{S} \times n_{S}
\end{array}\right]\left[\begin{array}{c}
E_{t} \bar{F}_{t+1} \\
n_{F} \times 1 \\
E_{t} \bar{S}_{t+1} \\
n_{S} \times 1
\end{array}\right]=\left[\begin{array}{cc}
B_{11} & B_{12} \\
n_{F} \times n_{F} & n_{F} \times n_{S} \\
B_{21} & B_{22} \\
n_{S} \times n_{F} & n_{S} \times n_{S}
\end{array}\right]\left[\begin{array}{c}
\bar{F}_{t} \\
n_{F} \times 1 \\
\bar{S}_{t} \\
n_{S} \times 1
\end{array}\right]+\left[\begin{array}{c}
C_{1} \\
n_{S} \times n_{E} \\
C_{2} \\
n_{S} \times n_{E}
\end{array}\right] \begin{gathered}
\bar{E}_{t} \\
\left(n_{F}+n_{S}\right) \times n_{E}
\end{gathered},
$$

where

$n_{F}$ : number of non-predetermined variables;

$n_{S}$ : number of predetermined variables;

$n_{E}$ : number of exogenous stochastic processes;

$\bar{F}_{t}=\left[\widehat{Y}_{t}\left|\widehat{C}_{t}\right| \widehat{I}_{t}\left|\widehat{\widetilde{C}}_{t}\right| \widehat{N}_{t}\left|\pi_{t}\right| \widehat{q}_{t}\left|\widetilde{r}_{t}\right| \widehat{r}_{t}^{k}\left|\widehat{w}_{t}\right| \widehat{M C}_{t} \mid \widehat{\tau}_{t}\right]^{\prime}$ contains the forward looking variables;

$\bar{S}_{t}=\left[\widetilde{r}_{t-1}\left|\widehat{\tau}_{t-1}\right| \widehat{l}_{t}\left|\widehat{m}_{t-1}\right| \widehat{K}_{t}\right]^{\prime}$ is the vector of predetermined variables; 
$\bar{E}_{t}=\left[\widehat{G}_{t}\left|\widehat{\digamma}_{t}\right| u_{t}^{w}\left|\varepsilon_{t}^{r}\right| \varepsilon_{t}^{d}\right]^{\prime}$ is the vector of exogenously given stochastic processes evolving according to $\bar{E}_{t}=\Sigma \bar{E}_{t-1}+\bar{\varepsilon}_{t}$, with $\bar{\varepsilon}_{t}=\left[\varepsilon_{t}^{G}\left|\varepsilon_{t}^{\digamma}\right| u_{t}^{w}\left|\varepsilon_{t}^{r}\right| \varepsilon_{t}^{d}\right]^{\prime}$ defined as the vector of white noises and $\Sigma$ being the $n_{E} \times n_{E}$ diagonal matrix reporting the autoregressive coefficients of the exogenous variables. The relevant matrices of the system depend on the fiscal rule adopted by the government.

The multivariate linear rational expectations model can be solved by applying the algorithm proposed by Klein (2000), which is based on the generalized Schur decomposition. We have applied Klein's algorithm to solve the model under the alternative fiscal rules defined in the main text.

\section{Appendix E: 'Active' and 'Passive' Fiscal Policy}

After substituting the tax rule (34) into (A.31), government liabilities evolve as

$$
\widehat{l}_{t+1}=R\left[\left(1-\tau_{l}\right) \widehat{l}_{t}-\frac{d}{Y} \pi_{t}+\widehat{G}_{t}-\tau_{Y} \widehat{Y}_{t}\right]+s_{b} \widetilde{r}_{t}-(R-1) s_{m} \widehat{m}_{t}
$$

Under the tax rule (34), stability of the government liabilities process requires that the coefficient on $\widehat{l}_{t}$ be less than one, so that fiscal policy is passive (active) if and only if $\left|R\left(1-\tau_{l}\right)\right|<(>) 1$. Hence, the restriction $\left|R\left(1-\tau_{l}\right)\right|<1$ rules out any explosive path of the government liabilities.

\section{References}

Annicchiarico, B. and A. Piergallini (2006), Monetary Rules and Deficit Shocks. Spanish Economic Review 9, 39-57.

Annicchiarico, B., Marini, G. and A. Piergallini (2008), Monetary Policy and Fiscal Rules. The B.E. Journal of Macroeconomics (Contributions) 8(1), Article 4.

Ascari, G. and N. Rankin (2007), Perpetual Youth and Endogenous Labour Supply: A Problem and a Possible Solution. Journal of Macroeconomics 29, 708-723.

Ascari, G. and N. Rankin (2007), Taylor Rules Cause Fiscal Policy Ineffectiveness. CDMA Conference Paper Series, No. 0707.

Benigno, G. and P. Benigno (2006), Designing Targeting Rules for International Monetary Cooperation. Journal of Monetary Economics 53, 473-506.

Bullard, J. and K. Mitra (2002), Learning about Monetary Policy Rules. Journal of Monetary Economics 49, 1105-1129.

Blanchard, O. J. (1985), Debt, Deficits, and Finite Horizons. Journal of Political Economy 93, 223247. 
Blanchard, O. J. and R. Perotti (2002), An Empirical Characterization of the Dynamic Effects of Changes in Government Spending and Taxes on Output. Quarterly Journal of Economics 117, 13291368.

Brock, W. A. (1975), A Simple Perfect Foresight Monetary Model. Journal of Monetary Economics $1,133-150$.

Calvo, G.A. (1983), Staggered Prices in a Utility Maximizing Framework. Journal of Monetary Economics 12, 383-398.

Clarida, R., Galí, J. and M. Gertler (1998), Monetary Policy Rules in Practice: Some International Evidence. European Economic Review 42, 1033-1067.

Clarida, R., Galí, J. and M. Gertler (1999), The Science of Monetary Policy: A New Keynesian Perspective. Journal of Economic Literature 37, 1661-1707.

Clarida, R., Galí, J. and M. Gertler (2000), Monetary Rules and Macroeconomic Stability: Evidence and Some Theory. Quarterly Journal of Economics 15, 147-180.

Fagan, G., Henry, J. and R. Mestre (2005), An Area-Wide Model (AWM) for the Euro Area. Economic Modelling 22, 39-59.

Favero, C. and T. Monacelli (2003), Monetary-Fiscal Mix and Inflation Performance: Evidence from the U.S. IGIER - Università Bocconi, Working Paper 234.

Favero, C. and T. Monacelli (2005), Fiscal Policy Rules and Regime (In)Stability: Evidence from the U.S. IGIER - Università Bocconi, Working Paper 282.

Frenkel, J. A. and A. Razin (1986), Fiscal Policies in the World Economy. Journal of Political Economy 94, 564-594.

Galí, J. (2008), Monetary Policy, Inflation and the Business Cycle. Princeton University Press.

Galí, J. and M. Gertler (2007), Macroeconomic Modeling for Monetary Policy Evaluation. Journal of Economic Perspectives 21, 25-45.

Galí, J., Gertler, M. and J.D. Lopéz-Salido (2001), European Inflation Dynamics. European Economic Review 45, 1237-1270.

Galí, J., López-Salido, D. and J. D. Vallés (2004), Rule-of-Thumb Consumers and the Design of Interest Rate Rules. Journal of Money, Credit, and Banking 36, 739-764.

Galí, J., López-Salido, D. and J.D. Vallés (2007), Understanding the Effects of Government Spending on Consumption. Journal of the European Economic Association 5, 227-270.

Galí, J. and R. Perotti (2003), Fiscal Policy and Macroeconomic Integration in Europe. Economic Policy 37, 533-572.

Gerlach, S. and G. Schnabel (2000), The Taylor Rule and Interest Rates in the EMU Area. Economics 
Letters 67, 165-171.

Goodfriend, M. and R.G. King (1997), The New Classical Synthesis and the Role of Monetary Policy. NBER Macroeconomic Annual 12, 231-283.

Judd, L.P. and G.D. Rudebusch (1998), Taylor's Rule and the Fed: 1970-1997. Federal Reserve Bank of San Francisco Economic Review 3, 3-16.

Klein, P. (2000), Using the Generalized Schur Form to Solve a Multivariate Linear Rational Expectations Model. Journal of Economic Dynamics \& Control 24, 1405-1423.

King, R. and M. Watson (1996), Money, Prices, Interest Rates and the Business Cycle. Review of Economics and Statistics 78, 35-53.

Leeper, E. (1991), Equilibria under 'Active' and 'Passive' Monetary and Fiscal Policies. Journal of Monetary Economics 27, 129-147.

Leith, C. and S. Wren-Lewis (2000), Interactions between Monetary and Fiscal Policy Rules. The Economic Journal 110, C93-C108.

Leith, C. and L. von Thadden (2008), Monetary and Fiscal Policy Interactions in a New Keynesian Model with Capital Accumulation and Non-Ricardian Consumers. Journal of Economic Theory 140, 279-313.

Marini, G. and F. Van der Ploeg (1988), Monetary and Fiscal Policy in an Optimizing Model with Capital Accumulation and Finite Lives. The Economic Journal 98, 772-786.

McCallum, B.T. (2001), Should Monetary Policy Respond Strongly to Output Gaps? American Economic Review Papers and Proceedings 91, 258-262.

McCallum, B.T. (2003), Multiple-Solution Indeterminacies in Monetary Policy Analysis. Journal of Monetary Economics 50, 1153-1175.

McCallum, B.T. and E. Nelson (1999a), Performance of Operational Policy Rules in an Estimated Semiclassical Structural Model, in J.B. Taylor (ed.), Monetary Policy Rules, Chicago and London: The University of Chicago Press, 15-56.

McCallum, B.T. and E. Nelson (1999b), An Optimizing IS-LM Specification for Monetary Policy and Business Cycle Analysis. Journal of Money, Credit and Banking 31, 296-316.

Mountford, A. and H. Uhlig (2008), What Are the Effects of Fiscal Policy Shocks? NBER Working Paper No. 14551.

Orphanides, A. (2001), Monetary Policy Rules Based on Real-Time Data.

American Economic Review 91, 964-985.

Orphanides, A. (2003), Historical Monetary Policy Analysis and the Taylor Rule. Journal of Monetary Economics 50, 983-1022. 
Perotti, R. (2002), Estimating the Effects of Fiscal Policy in OECD Countries. ECB Working Paper Series 168 .

Piergallini, A. (2006), Real Balance Effects and Monetary Policy. Economic Inquiry 44, 497-511.

Rotemberg, J. and M. Woodford (1997), An Optimizing-Based Econometric Framework for the Evaluation of Monetary Policy, in Bernanke, B., Rotemberg J. (eds), NBER Macroeconomic Annual, Cambridge MA: The MIT Press, 297-346.

Rotemberg, J. and M. Woodford (1999), Interest Rate Rules in an Estimated Sticky Price Model, in J.B. Taylor (ed.), Monetary Policy Rules, Chicago and London: The University of Chicago Press, 57-119.

Sauer, S. and J.E. Sturm (2007), Using Taylor Rules to Understand ECB Monetary Policy. German Economic Review 8, 375-398.

Schmitt-Grohé, S. and M. Uribe (2000), Price Level Determinacy and Monetary Policy under a Balanced-Budget Requirement. Journal of Monetary Economics 45, 211-246.

Schmitt-Grohé, S. and M. Uribe (2004), Optimal Simple and Implementable Monetary and Fiscal Rules. Journal of Monetary Economics 54, 1702-1725.

Sidrauski, M. (1967), Rational Choice and Patterns of Growth in a Monetary Economy, American Economic Review 57, 534-544.

Sims, C.A. (1988), Identifying Policy Effects, in: Bryant, R.C. et al., Empirical Macroeconomics for Interdependent Economies, The Brookings Institutions, Washington, D.C, 305-321.

Smets, F. and R. Wouters (2002), Openness, Imperfect Exchange Rate Pass-Through and Monetary Policy. Journal of Monetary Economics 49, 947-981.

Smets, F. and R. Wouters (2003), An Estimated Stochastic Dynamic General Equilibrium Model of the Euro Area. Journal of European Economic Association 1, 1123-1175.

Taylor, J.B. (1993), Discretion Versus Policy Rules in Practice. Carnegie-Rochester Conference Series on Public Policy 39, 195-214.

Taylor, J. B. (1999a), Monetary Policy Rules. Chicago: The University of Chicago Press.

Taylor, J. B. (1999b), A Historical Analysis of Monetary Policy Rules, in J.B. Taylor (ed.), Monetary Policy Rules, Chicago: University of Chicago Press, 319-347.

Taylor, J.B. (2000a), The Policy Rule Mix: A Macroeconomic Policy Evaluation, in Guillermo Calvo, Rudi Dornbusch, and Maurice Obstfeld (eds.) Money, Capital Mobility and Trade, Essays in Honor of Robert Mundell, MIT Press, 505-518.

Taylor, J.B. (2000b), Reassessing Discretionary Fiscal Policy. Journal of Economic Perspectives 14, $21-36$.

Woodford, M. (2001), The Taylor Rule and Optimal Monetary Policy. American Economic Review 
91, 232-237.

Woodford, M. (2003), Interest and Prices. Princeton and Oxford: Princeton University Press.

Yaari, M.E. (1965), Uncertain Lifetime, Life Insurance, and the Theory of the Consumer. The Review of Economic Studies 32, 137-150. 
Table 1: Calibration

\begin{tabular}{lll}
\hline \hline Baseline Calibration & & \\
\hline Steady state real interest rate & $r$ & 0.01 \\
Steady state public spending to output ratio & $G / Y$ & 0.2 \\
Steady state investment to output ratio & $I / Y$ & 0.2 \\
Steady state public debt to output ratio & $b / Y$ & 2.4 \\
Steady state money velocity & $P Y / M$ & 0.925 \\
Steady state time in employment & $N$ & $1 / 3$ \\
Probability of death & $\lambda$ & 0.015 \\
Inverse of the (Frisch) labor supply elasticity & $\varphi$ & 0.47 \\
Degree of price stickiness & $\theta$ & 0.75 \\
Elasticity of output with respect to capital & $\alpha$ & 0.3 \\
Depreciation rate & $\delta$ & 0.025 \\
Degree of inertia in the monetary rule & $\rho^{r}$ & 0.9 \\
Degree of inertia in the balanced-budget rule & $\rho^{d}$ & 0.9 \\
\hline \hline Implied Parameters & & 0.998 \\
\hline Discount factor & $\beta$ & 0.018 \\
Weight of money in the utility function & $\gamma$ & 0.6 \\
Consumption to output ratio & $C / Y$ & 8.0 \\
Capital to output ratio & $K / Y$ & 0.024 \\
Steady state primary surplus to output ratio & $(\tau-G) / Y$ \\
Consumption to subsistence consumption ratio & $C /(C-\widetilde{C})$ & 3.0 \\
Price mark-up & $u^{p}$ & 0.071 \\
Steady state wage mark-up & $u^{w}$ & 0.092 \\
\hline \hline Shocks & $\rho_{G}$ & 0.966 \\
\hline Persistence of public spending shock & $\rho_{\digamma}$ & 0.958 \\
Persistence of technology shock & $\sigma_{G}$ & 0.001 \\
Standard deviation of public spending shock & 0.001 \\
Standard deviation of monetary shock & $\sigma_{r}$ & 0.003 \\
Standard deviation of wage-push shock & $\sigma_{u^{w}}$ & 0.005 \\
Standard deviation of technology shock & $\sigma_{\digamma}$ & \\
\hline & & \\
\hline
\end{tabular}


Table 2: Simulation Results under a Passive Tax Rule

\begin{tabular}{llllll}
\hline \hline \multirow{2}{*}{ Values of $\tau_{l}, \tau_{Y}$} & \multicolumn{5}{l}{ Values of $\phi_{\pi}, \phi_{Y}$} \\
\cline { 2 - 6 } & $1.5,0.0$ & $3.0,0.0$ & $1.5,0.125$ & $3.0,0.125$ & \\
\hline \multirow{3}{*}{$0.1,0.0$} & 0.29 & 0.12 & 1.25 & 0.32 & $\sigma_{\pi}$ \\
& 3.33 & 3.43 & 4.04 & 3.50 & $\sigma_{\widehat{Y}}$ \\
& 0.26 & 0.20 & 1.08 & 0.37 & $\sigma_{\widetilde{r}}$ \\
& 2.98 & 3.10 & 3.10 & 3.06 & $\sigma_{\widehat{q}}$ \\
\hline \multirow{3}{*}{$0.5,0.0$} & & & & & \\
& 0.29 & 0.12 & 1.23 & 0.32 & $\sigma_{\pi}$ \\
& 3.34 & 3.51 & 3.98 & 3.55 & $\sigma_{\widehat{Y}}$ \\
$0.1,0.5$ & 0.26 & 0.20 & 1.06 & 0.37 & $\sigma_{\widetilde{r}}$ \\
& 2.98 & 3.15 & 3.10 & 3.09 & $\sigma_{\widehat{q}}$ \\
\hline & & & & & \\
& 0.30 & 0.13 & 1.15 & 0.32 & $\sigma_{\pi}$ \\
& 3.37 & 3.47 & 3.94 & 3.58 & $\sigma_{\widehat{Y}}$ \\
& 0.28 & 0.21 & 1.01 & 0.38 & $\sigma_{\widetilde{r}}$ \\
& 3.08 & 3.23 & 3.12 & 3.26 & $\sigma_{\widehat{q}}$ \\
\hline
\end{tabular}

Note: Table reports standard deviations of $\pi_{t}, \widehat{Y}_{t}, \widetilde{r}_{t}$, and $\widehat{q}_{t}$, respectively (percentages). 
Table 3: Simulation Results under an Active Tax Rule

\begin{tabular}{llllll}
\hline \hline \multirow{2}{*}{ Values of $\tau_{l}, \tau_{Y}$} & \multicolumn{5}{l}{ Values of $\phi_{\pi}, \phi_{Y}$} \\
\cline { 2 - 6 } & $0.0,0.0$ & $0.5,0.0$ & $0.8,0.125$ & $1.0,0.125$ & \\
\hline \multirow{3}{*}{$0.0,0.0$} & 0.47 & 0.59 & 1.01 & 1.29 & $\sigma_{\pi}$ \\
& 2.82 & 2.80 & 2.17 & 2.39 & $\sigma_{\widehat{Y}}$ \\
& 0.19 & 0.30 & 0.76 & 1.08 & $\sigma_{\widetilde{r}}$ \\
& 2.41 & 2.45 & 2.20 & 2.41 & $\sigma_{\widehat{q}}$ \\
\hline \multirow{3}{*}{$0.0,0.5$} & & & & \\
& 0.94 & 1.24 & 1.55 & 2.85 & $\sigma_{\pi}$ \\
& 3.07 & 3.16 & 2.75 & 4.44 & $\sigma_{\widehat{Y}}$ \\
$0.0,0.8$ & 0.20 & 0.44 & 0.91 & 2.10 & $\sigma_{\widetilde{r}}$ \\
& 2.87 & 3.01 & 2.74 & 4.36 & $\sigma_{\widehat{q}}$ \\
\hline & 1.03 & 1.40 & 1.92 & 9.46 & $\sigma_{\pi}$ \\
& 3.28 & 3.48 & 3.30 & 14.27 & $\sigma_{\widehat{Y}}$ \\
& 0.19 & 0.48 & 1.10 & 7.15 & $\sigma_{\widetilde{r}}$ \\
& 3.15 & 3.40 & 3.34 & 14.76 & $\sigma_{\widehat{q}}$ \\
\hline
\end{tabular}

Note: Table reports standard deviations of $\pi_{t}, \widehat{Y}_{t}, \widetilde{r}_{t}$, and $\widehat{q}_{t}$, respectively (percentages). 
Table 4: Simulation Results under the Balanced-Budget Rule

\begin{tabular}{|c|c|c|c|c|c|c|c|}
\hline \multirow[b]{2}{*}{ Values of $\delta_{Y}$} & \multicolumn{7}{|c|}{ Values of $\phi_{\pi}, \phi_{Y}$} \\
\hline & $0.0,0.0$ & $0.8,0.0$ & $1.5,0.0$ & $3.0,0.0$ & $1.5,0.125$ & $3.0,0.125$ & \\
\hline \multirow{4}{*}{0.0} & 0.46 & 0.52 & 0.28 & 0.12 & 1.00 & 0.32 & $\sigma_{\pi}$ \\
\hline & 2.75 & 2.83 & 3.29 & 3.44 & 3.52 & 3.60 & $\sigma_{\widehat{Y}}$ \\
\hline & 0.19 & 0.27 & 0.25 & 0.20 & 0.83 & 0.37 & $\sigma_{\tilde{r}}^{T}$ \\
\hline & 2.47 & 2.48 & 2.86 & 3.08 & 2.62 & 3.00 & $\sigma_{\widehat{q}}$ \\
\hline \multirow{4}{*}{-0.1} & 0.72 & 0.62 & 0.28 & 0.18 & 1.01 & 0.32 & $\sigma_{\pi}$ \\
\hline & 2.72 & 2.85 & 3.32 & 3.43 & 3.54 & 3.58 & $\sigma_{\widehat{Y}}$ \\
\hline & 0.20 & 0.33 & 0.25 & 0.25 & 0.83 & 0.38 & $\sigma_{\widetilde{r}}$ \\
\hline & 2.48 & 2.46 & 2.89 & 3.02 & 2.61 & 3.05 & $\sigma_{\widehat{q}}$ \\
\hline \multirow{4}{*}{-0.5} & 1.09 & 0.97 & 0.61 & \multirow{4}{*}{ instability } & 1.05 & 0.66 & $\sigma_{\pi}$ \\
\hline & 3.52 & 2.96 & 3.29 & & 3.60 & 3.71 & $\sigma_{\widehat{Y}}$ \\
\hline & 0.19 & 0.52 & 0.51 & & 0.87 & 0.65 & $\sigma_{\widetilde{r}}^{I}$ \\
\hline & 3.40 & 2.51 & 2.71 & & 2.70 & 2.96 & $\sigma_{\widehat{q}}$ \\
\hline
\end{tabular}

Note: Table reports standard deviations of $\pi_{t}, \widehat{Y}_{t}, \widetilde{r}_{t}$, and $\widehat{q}_{t}$, respectively (percentages). 
Figure 1: Determinacy Space under a Tax Rule
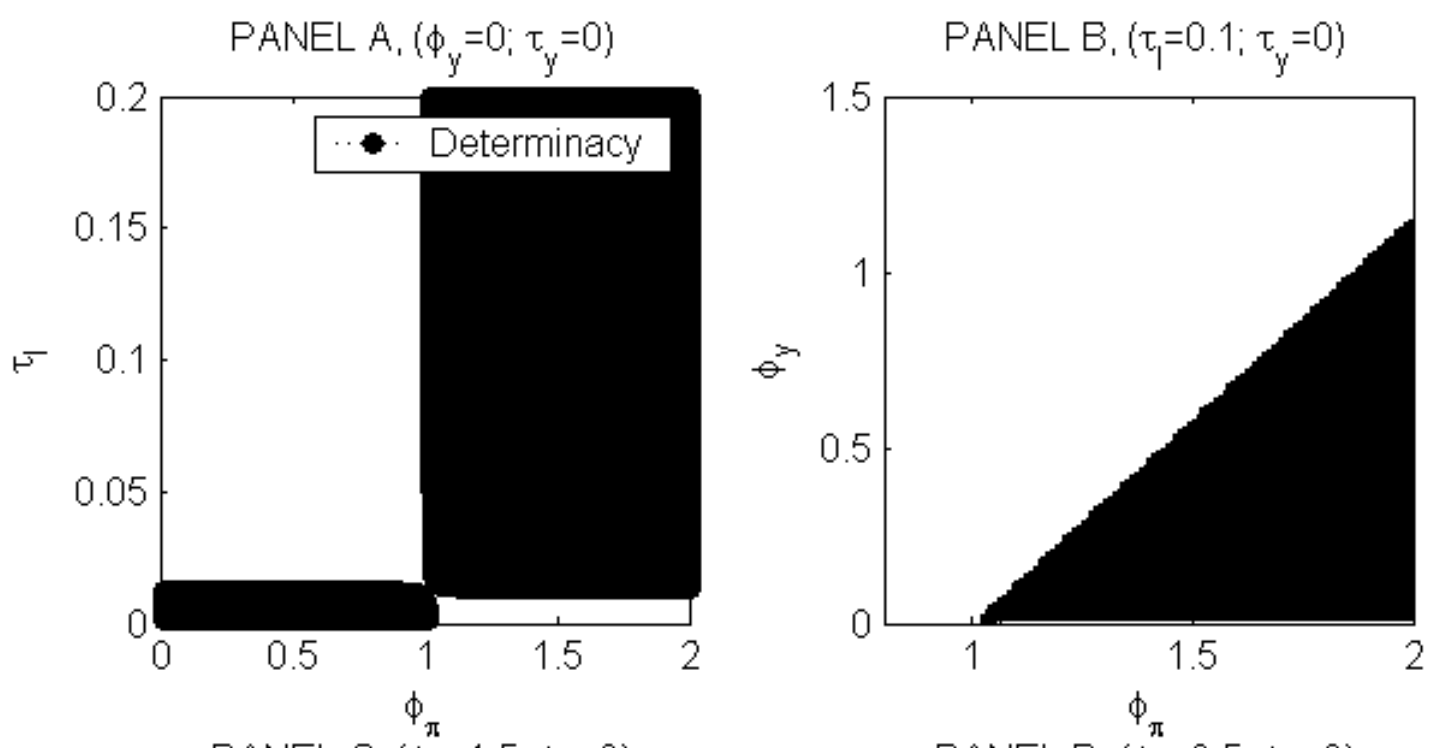

PANEL C,$\left(\phi_{\pi}=1.5 ; \phi_{y}=0\right)$
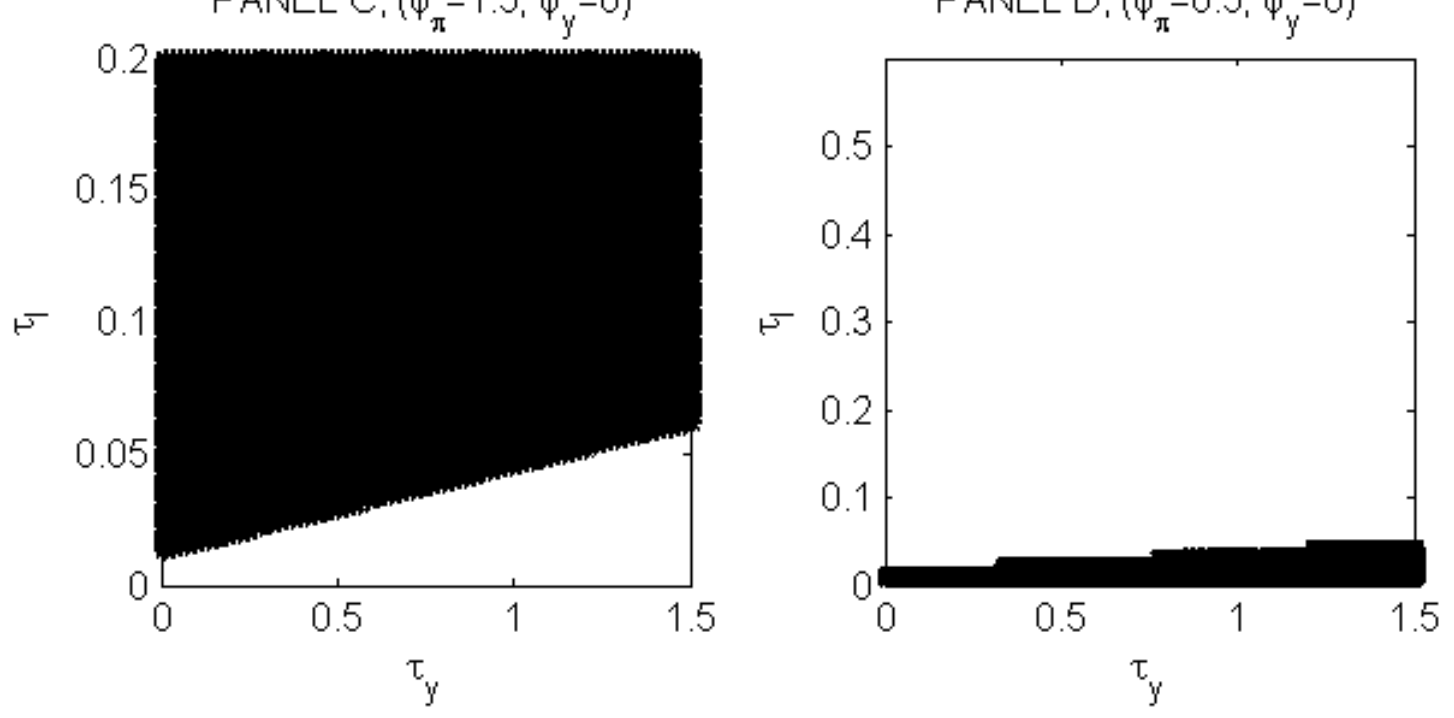
Figure 2: Impulse Response Functions to a Unit Government Spending Shock under a Tax Rule A: Passive Fiscal Policy and Active Monetary Policy
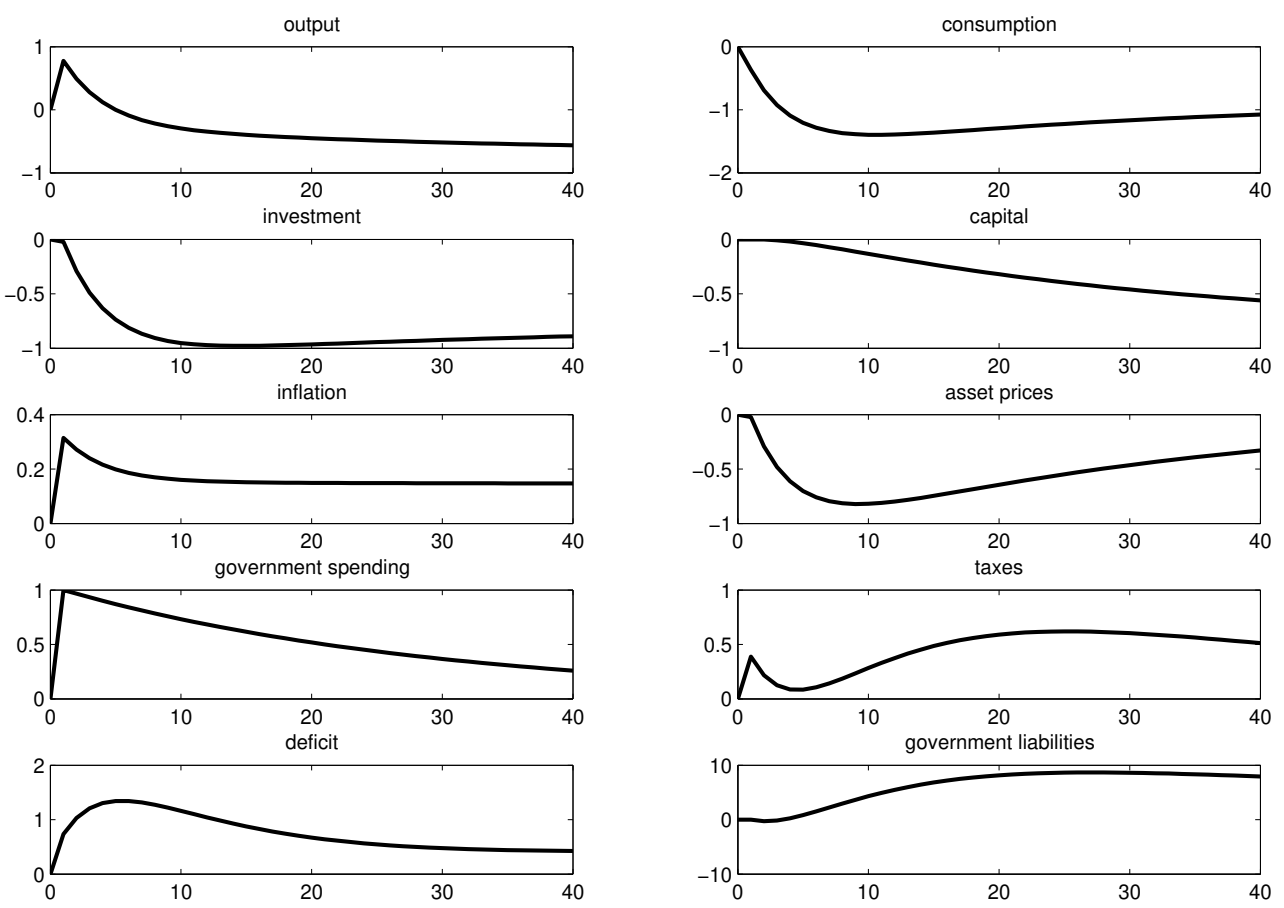

B: Active Fiscal Policy and Passive Monetary Policy
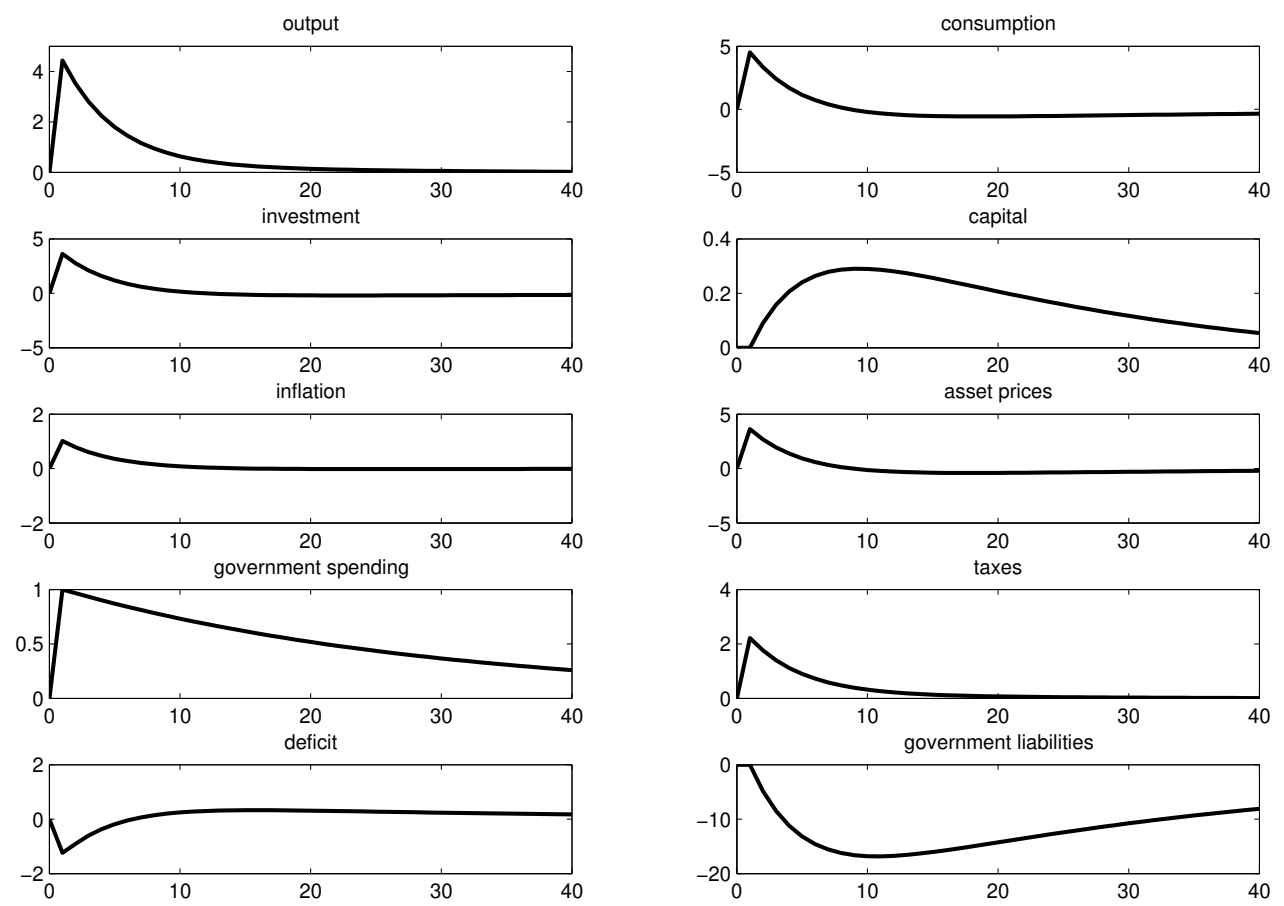
Figure 3: Determinacy Space under a Balanced-budget Rule
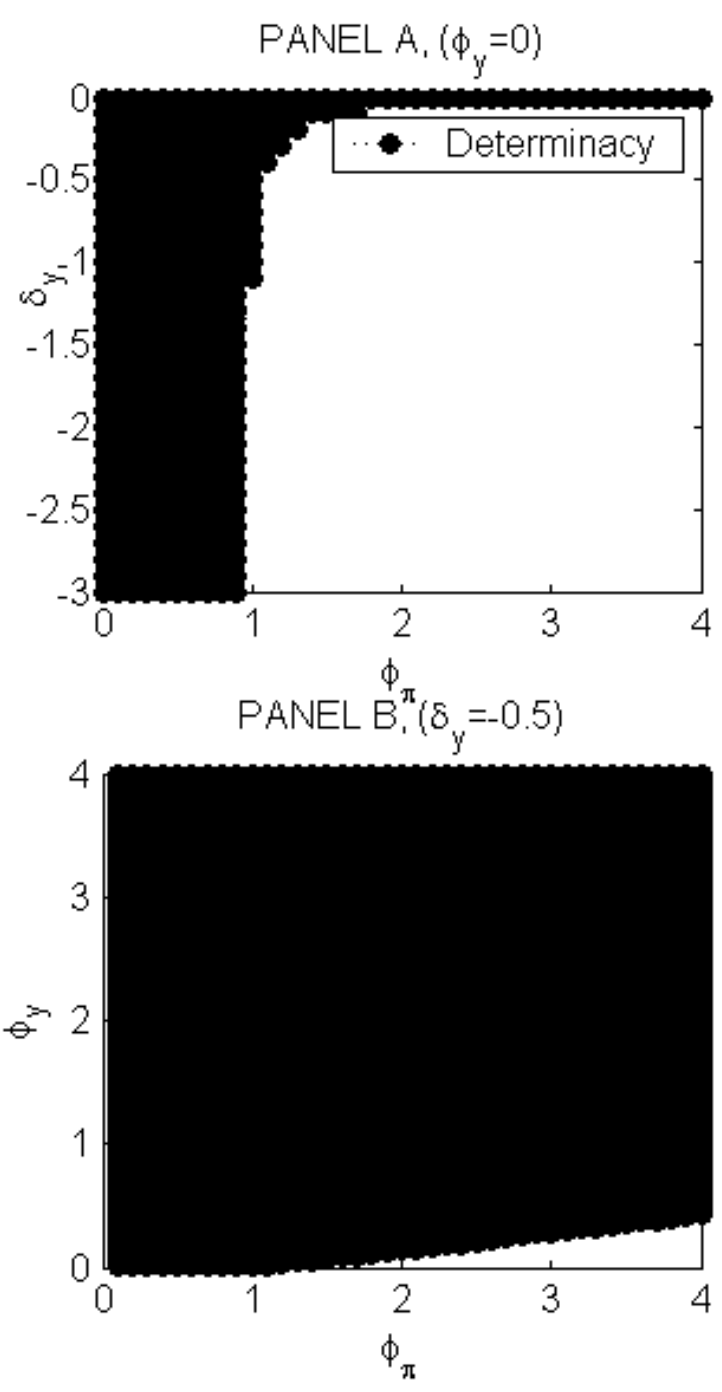
Figure 4: Impulse Response Functions to a Unit Government Spending Shock under a Balanced-budget Rule

A: Active Monetary Policy
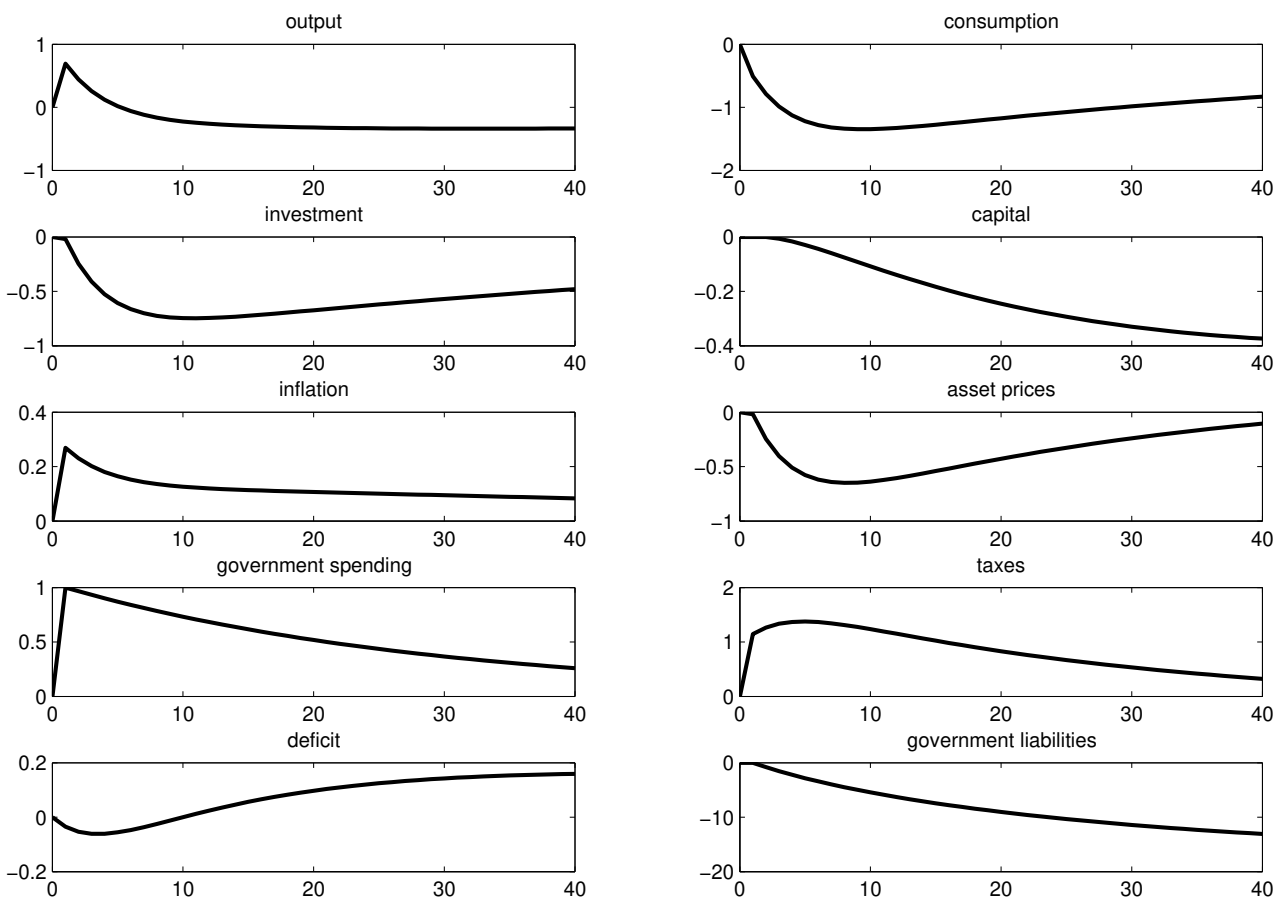

B: Passive Monetary Policy
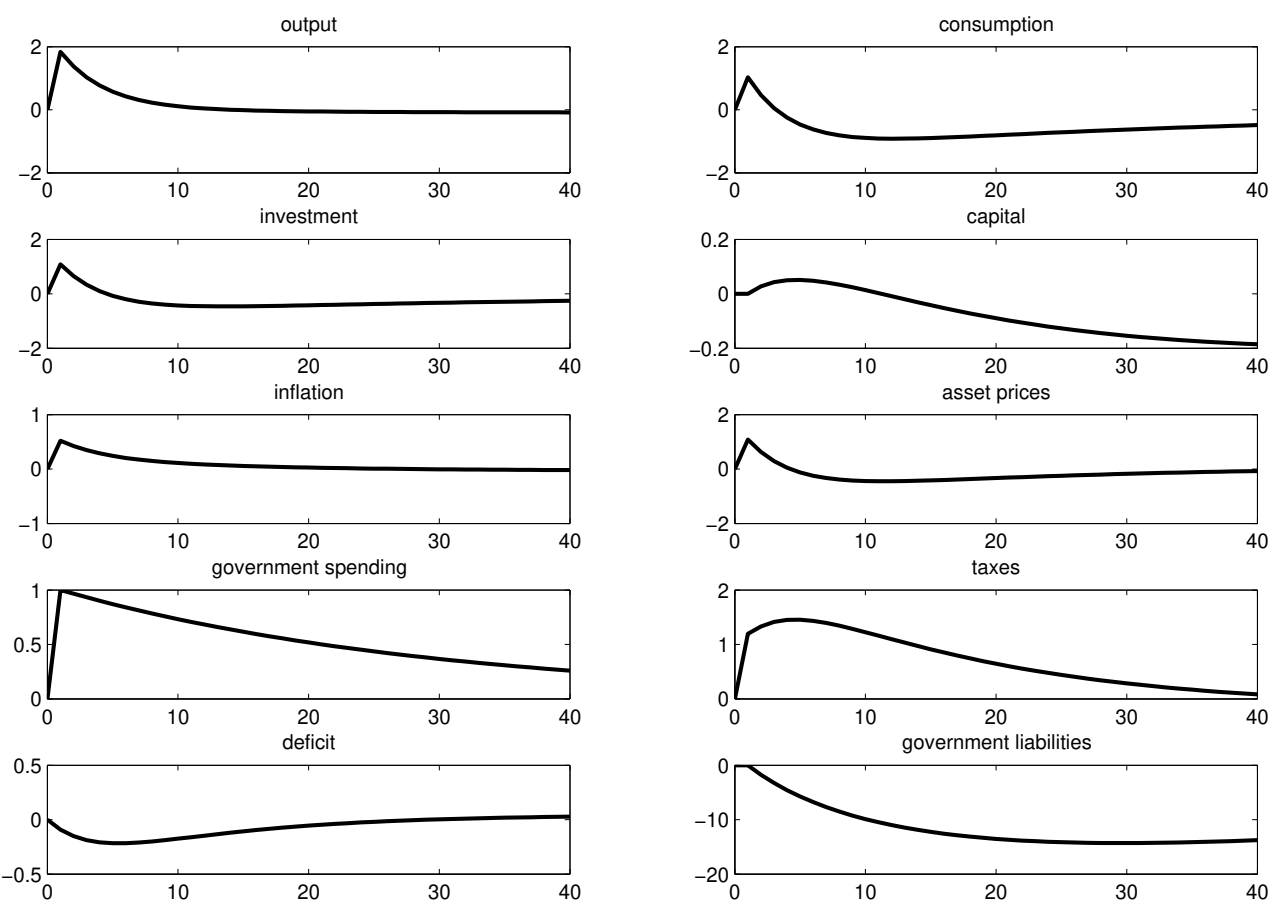